\title{
A model of fluff layer erosion and subsequent bed erosion in the presence of the bioturbator, Hydrobia ulvae
}

\author{
by Francis Orvain ${ }^{1,2}$, Pierre Le Hir ${ }^{3}$ and Pierre-Guy Sauriau ${ }^{1}$
}

\begin{abstract}
Previous studies have shown that the gastropod Hydrobia ulvae destabilizes the top layers of fine-grained sediments. This process is mediated by the formation of a "biogenic" fluff layer that includes tracks, faecal pellets and mucus. This fluff layer has been shown to be easily resuspended before general bed erosion. In order to examine how fluff layer and bed erosion interact, flume experiments were performed with fluid sediments of varying water contents. Ten thousand snails were placed and allowed to crawl for $5 \mathrm{~h}$ on the sediment surface, and then the resuspended sediment mass was measured in response to step-wise shear stress increases. Two distinct erosion phases were observed: (1) initial resuspension of the fluff layer and (2) the subsequent bed erosion. Both the bioturbation by snails and sediment water content interacted positively to increase erosion rates during the phase of fluff layer erosion. The presence of a fluff layer due to the snail's activities did not affect rates of subsequent bed erosion. A vertical model (1DV) was developed to simulate the succession in time of the two distinct erosion phases. Within this deterministic model, erosion rates of the fluff layer depend on the quantity of sediment that is present in the fluff layer. Previous behavioral observations of track formation mechanisms were integrated into model equations to account for the snail density and the water content dependence. The observed bed erosion was fairly well reproduced by considering the variation with depth of the sediment density as measured in the experiments. This model suggests a new approach for assessing the erosion of natural sediments under the influence of $H$. ulvae population density, water content and tidal currents.
\end{abstract}

\section{Introduction}

Mudflat sediments, subjected to tidal currents that cause episodic resuspension and deposition events, may consolidate during slack high tide periods and low tide periods of emersion. The cyclic nature of the resuspension and deposition events leads to the development of a vertical structure that can, in turn, create vertical variation in cohesive sediment erodibility. Bed erodibility (or the sediment bed's resistance to erosion) is described by two parameters: the critical threshold and erosion rate (Amos et al., 1992, 1997). The mode of erosion and the quantity of eroded sediment both vary with the

1. CREMA (CNRS-IFREMER UMR 10), Centre de Recherche sur les Ecosystèmes Marins et Aquacoles de L'Houmeau, Place du Séminaire, BP 5, 17137 L'Houmeau, France.

2. Present address: Laboratoire de Biologie et Biotechnologie Marine, Université de Caen, 14032 Caen Cedex, France.email:F.Orvain@iutcaen.unicaen.fr

3. IFREMER, Centre de Brest, DEL/EC-TP, BP 70, 29280 Plouzané, France. 
magnitude of the bed shear stress and the structure of the sediment bed (Mehta and Partheniades, 1982; Mehta, 1988).

The critical threshold is defined as the point in time when large quantities of sediment are resuspended rapidly from a sediment bed. This critical threshold is related to geotechnical properties, principally water content and sediment density (Mehta and Partheniades, 1982; Amos et al., 1988, 1992). Depending on the consolidation status of sediment bed affecting water content profile, different modes of erosion (for soft and dense beds) are classically described (Mehta, 1988; Amos et al., 1992). Both modes of erosion are able to co-occur on the same station in the field (Amos et al., 1992). However, the sediment-water interface is not defined by a sharp gradient but behaves as a continuum gradient (Pearson, 2001), and sometimes a single erosion threshold is difficult to establish. Particles may become resuspended at very low current flow velocities on fresh muddy deposits before the critical threshold for bed erosion is achieved (Lavelle and Mofjeld, 1987). This initial erosion, observed just before the critical threshold for bed erosion, is generally termed "fluff layer erosion" (Shimeta et al., 2002).

Fluff layer erosion had been described as ambient turbidity or the result of experimental artefacts, since such small quantities of sediment are involved. Currently, the importance of the fluff layer in sediment erosion studies has been recognized (Amos et al., 1997; Paterson and Black, 1999). The fluff layer is a matrix of sediment that is disconnected from the underlying sediment bed and it may include deposited aggregates, deposit-feeder tracks and faecal pellets, and disturbed sediment due to deposit-feeding activities. Macrofaunal populations are known to ingest resuspended particles (Willows et al., 1998, 2000a, b) and macrofaunal bioturbation can substantially enhance fluff layer erosion (Widdows et al., $2000 \mathrm{a}, \mathrm{b})$. For example, it has been demonstrated that bioturbation by the common mud snail, Hydrobia ulvae, enhances the erosion rates of consolidated, fine-grained surface sediments (Andersen et al., 2002; Orvain, 2002). However, the subsequent bed erosion was not observed in these studies.

A model developed by Willows et al. (1998) described the effects of the deposit-feeder, Macoma balthica, on surface destabilization. This model was suitable for describing surface sediment destabilization due to Hydrobia ulvae bioturbation activities (Orvain, 2002) but did not reproduce the bed erosion subsequent to fluff layer erosion. In order to model the effects of $H$. ulvae on the resuspension of natural sediments, data are required on both fluff layer erosion and bed erosion.

Jumars et al. (1981) proposed a model where faecal pellets produced by deposit-feeders are incorporated into a surface compartment that is allowed to behave differently from the underlying sediment bed. Inspired by their approach, we used flume experiments to examine the: (1) fluff layer erosion after a period of emersion and bioturbation and (2) the subsequent general bed erosion. The experiments were conducted on fluid, fine-grained mudflat sediments with varying water contents to quantify the effects of $H$. ulvae bioturbation on erosion properties. We modified an existing 1DV model of the SiAM series 


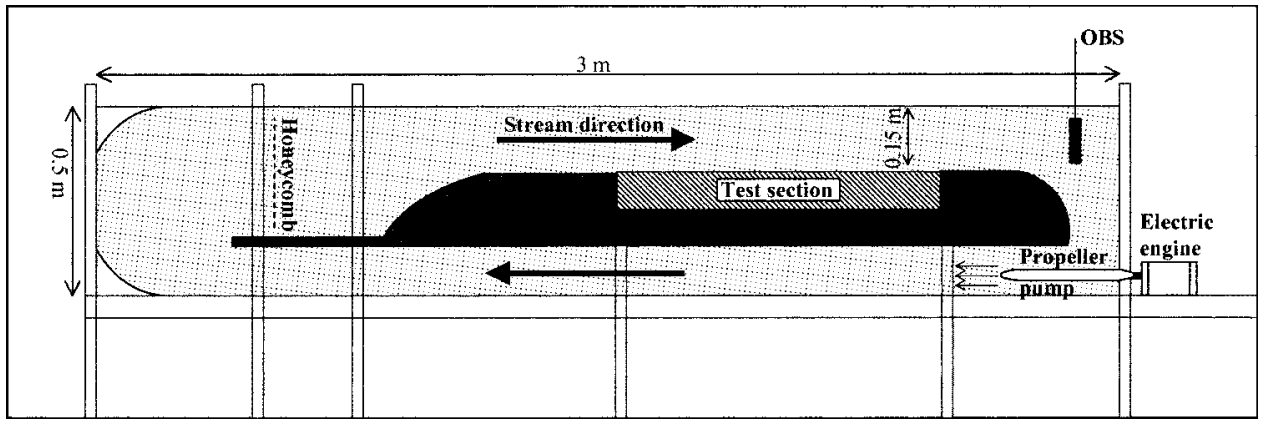

Figure 1. Schematic representation of the benthic flume used in the experiments.

(Brenon and Le Hir, 1999; Le Hir et al., 2001) to estimate the resuspension of a separate compartment that was the fluff layer generated by $H$. ulvae grazing activities.

\section{Flume experiments}

\section{a. Benthic flume}

The flume prototype, called HYDROBIOS ("HYDROdynamic \& BIOlogical Synergy" installed at the CREMA laboratory, L'Houmeau, France), is a $3 \mathrm{~m}$ long vertically recirculating flow system (Fig. 1), where water flow is generated by two turbines placed in the return pipe in the lower part of the flume. A frequency regulator regulates the propeller velocity and the system can generate free-stream velocities up to $0.6 \mathrm{~m} \mathrm{~s}^{-1}$, with an accuracy of $0.01 \mathrm{~m} \mathrm{~s}^{-1}$. The test section, where the sediment is located, is $0.40 \mathrm{~m}$ wide and $0.90 \mathrm{~m}$ long, and $1.80 \mathrm{~m}$ from the flow entrance. The width of the flume in the test section is half the size of the entrance width (i.e. $0.80 \mathrm{~m}$ ) in order to reduce wall effects.

The curved shape of the walls at the entrance and the use of a honeycomb grid $(10 \mathrm{~mm}$ grid diameter) placed across the full width of the entrance generated a fully turbulent and uniform flow across the test section. At the exit of the test section where upstream effects could occur, there was minimal interference at the test section and no sign of return circulation. The flume contained $1.16 \mathrm{~m}^{3}$ of filtered seawater when the water depth at the test section was $0.15 \mathrm{~m}$.

An ultrasonic velocity meter (Minilab system) was used to measure vertical flow profiles at 9 points in the test section. Estimates were made of flow heterogeneity over the section using bed shear stress, roughness length and Reynolds numbers. At each point, 8 current profiles were measured for 8 different propeller speeds (Fig. 2A) and for each profile, 17 velocity measurements were taken. The flume set-up produced a stable and unidirectional flow, assuring reproducibility of flow conditions. No signs of secondary circulation (such as a deviation of the flow from the main axis of the channel or anomalies in current profiles) were observed. 
A)
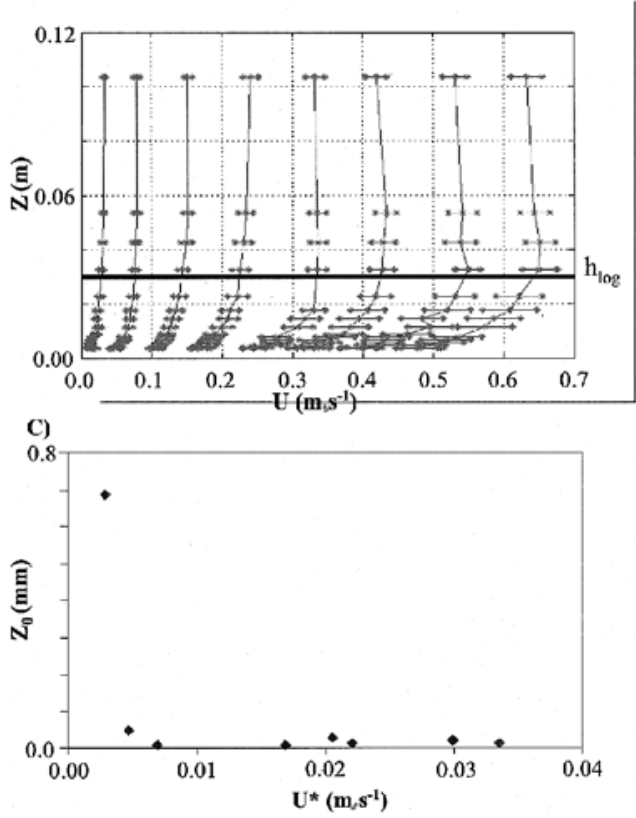

B)

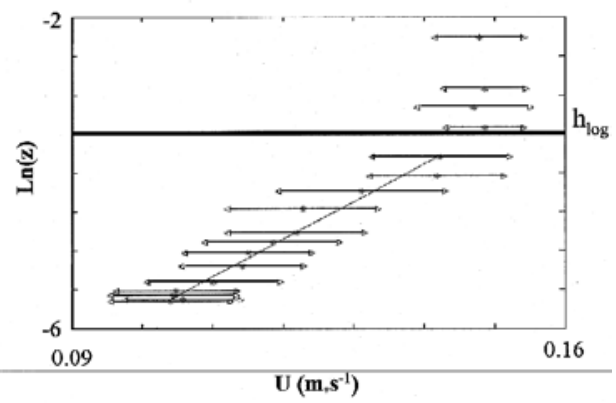

D)

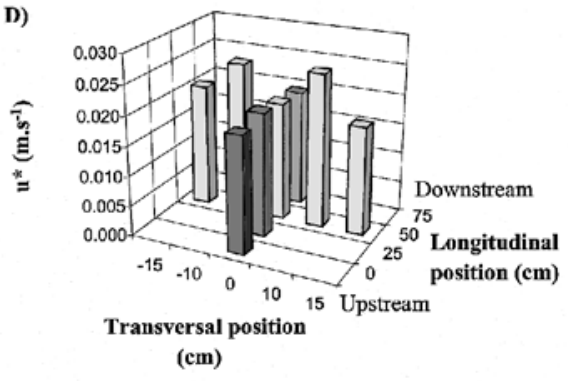

Figure 2. Characterization of the recirculating flume conditions: (A) Velocity profiles measured at the center of the test section for 8 different propeller velocities. For each profile, velocity measurements were made at 17 different depths, $z$, from the bottom $(n=2000)$. (B) Relationship between $\ln (z)$ and $u(z)$ within logarithmic and infinite layers; Averaged values of $u(z)$ (crosses) \pm $S D$ (triangles) are given. (C) Relationship between the roughness length $\left(z_{0}\right)$ and shear velocity $\left(u^{*}\right)$ at the center of the test section. (D) Spatial heterogeneity of the averaged friction velocity $\left(u^{*}\right)$ on the test section of the flume for $u_{\infty}=0.5 \mathrm{~m} \mathrm{~s}^{-1}$.

Assuming a logarithmic profile, we used the so-called universal von Karman-Prandtl "law of the wall" relationship within the logarithmic layer:

$$
u(z)=\frac{u^{*}}{k} \ln \left(\frac{z}{z_{0}}\right)
$$

where, $u(z)$ is the mean horizontal velocity at height $z\left(\mathrm{~m} \mathrm{~s}^{-1}\right), u^{*}$ is the friction velocity $\left(\mathrm{m} \mathrm{s}^{-1}\right), k$ is the von Karman's constant (0.41) and $z_{0}$ is the roughness length $(\mathrm{m})$. The shear velocity and the roughness length were deduced from the logarithmic part of the flow profile (Fig. 2B) where the plot of $u(z)$ versus $\ln (z)$ gives a linear relationship with a slope of $k / u^{*}$ and an intercept at $\ln \left(z_{0}\right)$. If the flow is smooth and turbulent (i.e. characterized by a boundary Reynolds number $\left.R e^{*}<5\right), z_{0}$ is proportional to the friction velocity and fluid viscosity $\left(v=1 \times 10^{-6} \mathrm{~m}^{2} \mathrm{~s}^{-1}\right)$, such that $z_{0}=0.11 \mathrm{v} / u^{*}$. If the flow is rough and turbulent (i.e. for $R e^{*}>70$ ), $z_{0}$ is a function of the roughness of the bed (denoted by $k_{s}$ ) such that $z_{0}=k_{s} / 30$. If the bed is flat (i.e. not covered by ripples), $k_{s}$ is termed the 
"Nikuradse roughness" and is a function of grain size ( $D$ in $\mathrm{m})$. For the flat muddy bed we used, we obtained a dependence of $z_{0}$ on shear velocity (Fig. 2C), which suggested a hydraulically smooth boundary. To verify this, we calculated the boundary Reynolds number for the eight current profiles measured at the center of the test section. This calculation holds:

$$
R e^{*}=\frac{u^{*} D}{v}
$$

Even when considering a high grain diameter of $100 \mu \mathrm{m}$, we obtained a maximum $R e^{*}$ value of 3.3, which is below the limit of 5 that characterizes a hydraulically smooth boundary.

Bed shear stress $\left(\tau_{f}\right)$ was calculated from friction velocity according to: $\tau_{f}(P a)=\rho \times$ $u^{* 2}$, where $\rho=$ water density ( $1020 \mathrm{~kg} \mathrm{~m}^{-3}$ for the sea water used in our experiments). The top of the logarithmic layer $\left(h_{\log }\right)$ was always chosen as $20 \%$ of the water depth $(3 \mathrm{~cm})$, since this value systematically allowed the best $r^{2}$ in the determination of $u^{*}$ (Figs. 2A and 2B). The values of current velocities were not significantly different within the layer above $3 \mathrm{~cm}$ while a significant difference was obtained between the value of current velocity at $2 \mathrm{~cm}$ and those above $3 \mathrm{~cm}$. The infinite velocity $\left(u_{\infty}\right)$ is determined by averaging velocities measured above this distance from the bed $h_{\log }=3 \mathrm{~cm}$ to the water depth $(\delta)$ :

$$
u_{\infty}=\int_{h_{\log }}^{\delta} u d z .
$$

The relationship between $u^{*}, u_{\infty}$ and control frequency (denoted $F_{r}$ ) has been established from velocity profiles measured at the center of the test section. We obtained:

$$
u^{*}=4.58 \times 10^{-4} \times F_{r} \quad\left(r^{2}=0.97\right) \quad \text { and } \quad u^{*}=5.44 \times 10^{-2} \times u_{\infty} \quad\left(r^{2}=0.96\right) .
$$

Since resuspension begins where bed shear stress is at a local maximum, we estimated the spatial heterogeneity in units of bed shear stress. Using such a spatial characterization of the flow across the test section allowed us to calculate accurately the critical bed shear stress for resuspension and the succession of bed shear stresses during the experiments. These calculations showed only a transversal heterogeneity of bed shear stress and no longitudinal heterogeneity (Fig. 2D). Maximum bed shear stresses occurred on both sides of the middle part of the test section and the maximum bed shear stress was up to 1.25 times greater than the bed shear stress at the center. The maximum friction velocity was described by the following relationship:

$$
u_{\max }^{*}=4.58 \cdot 10^{-4} \times F_{r} \times 1.25 .
$$

The maximum bed shear stress on a test section was $1.6 \mathrm{~Pa}$ for the highest tested frequency. 
Table 1. Summary of sediment dry densities (in the topmost centimeter) and critical threshold for bed erosion of the three subsets of four experiments.

$\begin{array}{ccc}\text { Experimental subsets } & \begin{array}{c}\text { Dry densities } \\ \left(\mathrm{kg} \mathrm{m}^{-3}\right)\end{array} & \begin{array}{c}\text { Critical threshold for erosion } \\ \left(\tau_{b} \text { in Pa }\right)\end{array} \\ \text { Subset 1 } & \left\{\begin{array}{l}270.46 \pm 9.63 \\ 255.14 \pm 11.06 \\ 260.74 \pm 8.48 \\ 257.32 \pm 7.41\end{array}\right. \\ \text { Subset 2 } & \left\{\begin{array}{l}238.99 \pm 10.31 \\ 230.94 \pm 7.28\end{array}\right. \\ 227.62 \pm 5.74 & 1.38 \\ 245.04 \pm 9.49 & 0.90 \\ \text { Subset 3 } & \begin{cases}190.09 \pm 3.60 \\ 197.59 \pm 19.30\end{cases} \\ 185.62 \pm 18.62 & 0.82 \\ 189.44 \pm 5.70 & 0.80 \\ & \end{array}$

\section{b. Experimental procedures}

Experiments were designed to test two crossed factors: sediment density and snail density. Presence and absence of snails was tested ( 0 and 10,000 snails $\left.\mathrm{m}^{-2}\right)$ and three treatments for sediment dry densities (the targeted sediment dry densities were 260, 230 and $190 \mathrm{~kg} \mathrm{~m}^{-3}$, respectively denoted as subsets 1,2 and 3 in Table 1). Two duplicated experiments in each combination of the $3 \times 2$ factorial design were completed, so that a total of 12 flume experiments were conducted.

An "initial" stock of silty mud, characterized by $95 \%$ particles $<63 \mu \mathrm{m}$ on average and a mean size between 1 to $6 \mu \mathrm{m}$ (see Gouleau et al., 2000; Bassoulet et al., 2000 for a detailed description), was collected from Brouage mudflat in Marennes-Oléron Bay (SW France). Only deep and oxic layers $(10-20 \mathrm{~cm})$ were used for the stock mud to avoid any interaction with active diatom populations in the resuspension experiments. The mud was sieved $(<1 \mathrm{~mm})$ to remove the macrofauna and then homogenized at regular intervals during a storage period of 1 month.

Fluid sediments were prepared from this stock of "initial" sediment by adjusting the seawater volumes used for dilution at the beginning of each experiment such that the desired sediment dry densities would be achieved. The sediment dry density (i.e. $\rho_{d}$ in $\mathrm{kg} \mathrm{m}^{-3}$ ) was calculated from the water content using the following formula:

$$
\rho_{d}\left(\mathrm{~kg} \mathrm{~m}^{-3}\right)=\frac{\rho_{s} \cdot 1000}{w / 100 \cdot \rho_{s}+1000}
$$

where $\rho_{s}$ is the average grain density $\left(2650 \mathrm{~kg} \mathrm{~m}^{-3}\right)$ and $w$ is the water content (g water/g dry sediment $\times 100$ ) which was measured by drying at $60^{\circ} \mathrm{C}$ for 3 days. The actual dry densities between replicated experiments were different due to incomplete homogenization. Thus the dry density of each prepared sediment bed (denoted $\rho_{d}^{j}$ for each experiment 
j) was measured systematically (average dry densities were $260.91 \pm 6.77,235.65 \pm 7.88$ and $190.68 \pm 5.00 \mathrm{~kg} \mathrm{~m}^{-3}$ for the experiment subsets 1,2 and 3, respectively, see Table 1 for all values).

Experimental tanks were filled with prepared and mixed sediments and they were placed immediately in the flume. The validity of the independently measured shear stresses depended on our ability to reproduce similarly flat and smooth bottom topographies (as during flow profile measurements). It was desirable to minimize edge effects, especially where the sediment adjoined the upstream side of the flume base. To limit these effects, an additional $10 \mathrm{~d} \mathrm{~m}^{3}$ of prepared mud was spread over the tank bottom and was shaped to adjoin the flume bottom on both the downstream and upstream edges. Nevertheless, due to the nature of mass erosion, the bed roughness was expected to change locally during the resuspension experiments.

After the installation of the sediment test bed, the flume was filled with $10 \mu \mathrm{m}$ filtered seawater until a thin water layer $(5 \mathrm{~mm})$ appeared on the sediment surface. The salinity was adjusted systematically to between $30-31$ PSU. Next, 10,000 snails $\mathrm{m}^{-2}$ were added to the test section. The test bed was walled to prevent the snails from escaping. Snails are mobile only in the presence of water but they remained on the test section where they could actually climb on the walls at a distance equivalent to the water depth of $5 \mathrm{~mm}$ (Orvain and Sauriau, 2002). In such conditions, snails could: (1) crawl on sediment bed, (2) bury themselves if the upper layer of sediment is fluid (only for subset 3), (3) climb on walls at a distance equivalent to the 5-mm water depth and (4) float at water/air interface. Such a covering by a thin layer of water is encountered by snails in most of their habitats throughout natural low tide. After $5 \mathrm{~h}$ of bioturbation under these simulated low-tide conditions, walls were removed from the test bed and the flume was filled until the water column height reached $0.15 \mathrm{~m}$ without disturbing the sediment surface. The fluff layer was not washed away due to filling. Sediments without Hydrobia ulvae were treated the same way.

For each subset, small control boxes were filled with fluid mud that was prepared in a similar way to the flume sediments. Three cores were taken from these control boxes using syringes $(3 \mathrm{~cm}$ in diameter) to measure the depth profiles of the dry density. The three nonfrozen cores were sectioned every two millimeters over a total of two centimeters. There was little scatter in dry density of the superficial fluid layers (Fig. 3). The decrease in dry density of the topmost sediments was more pronounced for the most fluid sediments (i.e. subset 3) and this probably reflected the differential "sedimentation" that took place during the $5 \mathrm{~h}$ of simulated low tide.

Three simple logarithmic functions (i.e. for each profile, see equations in the description of Fig. 3) were fitted to the curves of dry density ( $\tilde{\rho}_{d(C)}^{i}$ for layer $i$ of controls) as a function of depth of the layer $z_{i}$ :

$$
\tilde{\rho}_{d(C)}^{i}=x_{1} \ln \left(z_{i}\right)+x_{2}
$$




\section{Dry density $\left(\mathrm{kg} \mathrm{m}^{-3}\right)$}

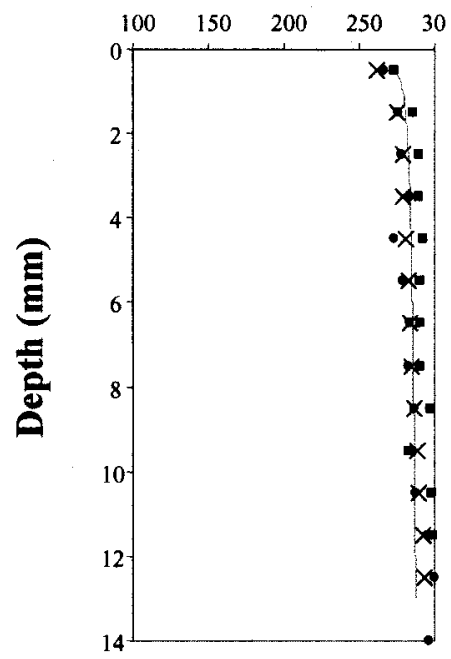

A)

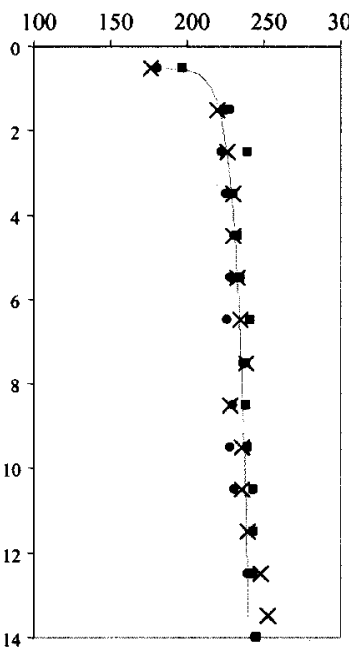

B)

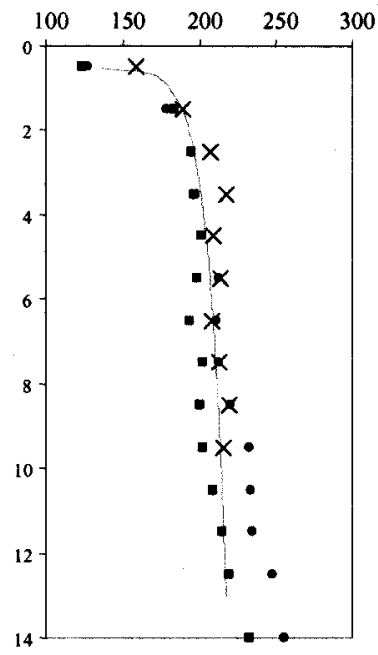

C)

Figure 3. Dry density profiles $(n=3$ ) of the three subsets 1,2 and 3 (A, B and C, respectively). Logarithmic equations were fitted to the measured profiles (solid lines). The adjusted equation is: $\tilde{\rho}_{d(C)}^{i}=x_{1} \ln \left(z_{i}\right)+x_{2}$, where $\tilde{\rho}_{d(C)}^{i}$ is the dry density in the section $i$ (from 1 to 10) of controls, $x_{1}$ and $x_{2}$ are the coefficients of the logarithmic profile ( 3 different values for each subset) and $z_{i}$ is the depth of the vertical section $(i)$.

Independent values of $\rho_{d(j)}^{0-1}$ (within the topmost centimeter for each experiment $j$; see Table 1) measured from the flume sediments were used to estimate the dry density profile typical of each experiment by the following formula:

$$
\tilde{\rho}_{d(j)}^{i}=\tilde{\rho}_{d(C)}^{i} \frac{\tilde{\rho}_{d(C)}^{0-1}}{\rho_{d(j)}^{0-1}}
$$

where, $\tilde{\rho}_{d(j)}^{i}$ is the estimated dry density within layer $i$ and for experiment $j, \tilde{\rho}_{d(C)}^{i}$ is the adjusted dry density within the layer $i$ of controls (Fig. 3), $\tilde{\rho}_{d(C)}^{0-1}$ is the dry density of adjusted profiles within the topmost centimeter of control sediments (Fig. 3) and $\rho_{d(j)}^{0-1}$ is the measured dry density within the topmost centimeter of each flume experiment $j$. Furthermore, critical thresholds were calculated in the models on the basis of these estimated dry density profiles to describe any specific differences due to experimental conditions and depth.

Sediment resuspension was quantified in response to stepwise increases in current velocity (14 increments, from 0 to $0.60 \mathrm{~m} \mathrm{~s}^{-1}$, each lasting $20 \mathrm{~min}$ ). Since the animals dispersed very rapidly and randomly during flume filling, no animals remained on the test section and thus did not influence bed roughness by their shells. Turbidity, measured as 
suspended particulate matter ( $\mathrm{SPM}$ in $\mathrm{kg} \mathrm{m}^{-3}$ ) in the flume was monitored at 15 -s intervals using an OBS (Optical Backscattering Sensor).

The turbidity calibration was conducted on samples taken at the end of every current increment. Water samples were taken from the downstream test section and preliminary tests were performed to check water column homogeneity at this location. Duplicate water subsamples $\left(1 \mathrm{~d} \mathrm{~m}^{3}\right)$ were immediately filtered through pre-weighed Whatman GF/C filters, which were dried at $50^{\circ} \mathrm{C}$ for 3 days after filtering and then re-weighed.

For each experiment, the probe turbidity time series were calibrated from the set of pooled $28 \times 12 \mathrm{SPM}$ data $\left(r^{2}=0.998 ; P<0.001\right)$. Resuspension data were converted into sediment mass eroded per unit area $\left(M\right.$ in $\left.\mathrm{kg} \mathrm{m}^{-2}\right)$ according to the formula: $M=$ $\operatorname{SPM}(V / S)$ where $V$ is the flume volume $\left(\mathrm{m}^{3}\right)$ and $S$ is the test section surface $\left(\mathrm{m}^{2}\right)$. This allowed us to make direct comparisons with in situ or other flume data. The threshold values of friction velocity for resuspension $\left(u_{c r}^{*}\right)$ were determined by regression of $S P M$ against $\log \left(u^{*}\right)$ in regions where $S P M$ increased monotonically (Sutherland et al., 1998). The best-fit regression lines of the data were searched by using a semi-logarithmic equation $S P M=A+B \log \left(u^{*}\right)$ to search for the inflexion point and the solution of the intercept with the baseline $S P M=0$ was calculated. The equivalent critical threshold values for bed erosion $\left(\tau_{b}\right)$ were then deduced according to: $\tau_{b}=\rho \times u_{c r}^{* 2}$.

\section{c. Resuspension results}

The values of critical threshold for bed erosion were clearly dependent on the sediment dry density (Table 1). Mean values of critical threshold for bed erosion were $1.16 \pm$ $0.23 \mathrm{~Pa}, 0.82 \pm 0.02 \mathrm{~Pa}$ and $0.65 \pm 0.10 \mathrm{~Pa}$ for subsets 1,2 and 3 , respectively. However, there was evidence in the resuspension data (Figs. 4A, 4C and 4E) that there was a fluff layer erosion before the inflexion in resuspension data at the critical threshold for bed erosion.

In all experiments, fluff layer erosion took place as soon as the critical threshold for fluff layer of $0.12 \mathrm{~Pa}$ was reached (Figs. 4A, 4C and 4E). Erosion of the fluff layer was gradual, and the erosion rates were low. After each flow increase, the amount of eroded material from the fluff layer increased measurably during a period of up to $5 \mathrm{~min}$, after which a plateau was reached. This suggests that all the material from fluff layer that was available for erosion at a particular bed shear stress was eroded rapidly. A new increase in bed shear stress was required to cause a new resuspension of material from the fluff layer. This gives rise to a very gradual resuspension of the fluff layer, and especially mucus-rich tracks, some of them being able to resist to current velocity up to $40 \mathrm{~cm} \mathrm{~s}^{-1}$ while the main part of tracks were eroded at lower current velocity (Figs. 4A, 4C and 4E).

During erosion of the fluff layer, higher quantities of sediment were resuspended after bioturbation by Hydrobia ulvae than without (Fig. 4). The crawling activities of snails during the 5-hour simulated low tide left tracks on the sediment surface. Substantial parts of fluff layer particles were incorporated in mucus-rich tracks that were produced by snails and that were gradually dislodged from the sediment bed to be easily eroded (visual 
Subset $1: \rho_{\mathrm{d}} \approx 260 \mathrm{~kg}_{\mathrm{s}} \mathrm{m}^{-3}$

(A)

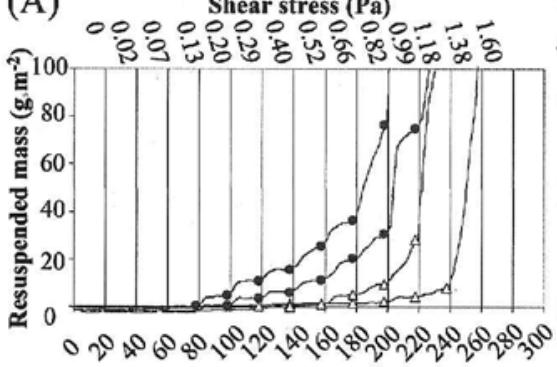

Time (min)
(B) Shear stress (Pa)

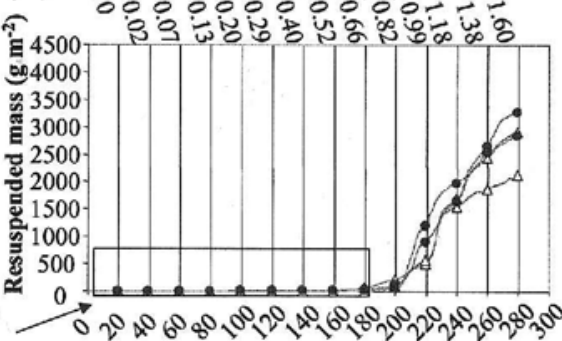

Time (min)

Subset $2: \rho_{d} \approx 235 \mathrm{~kg} \mathrm{~m}^{-3}$

(C)

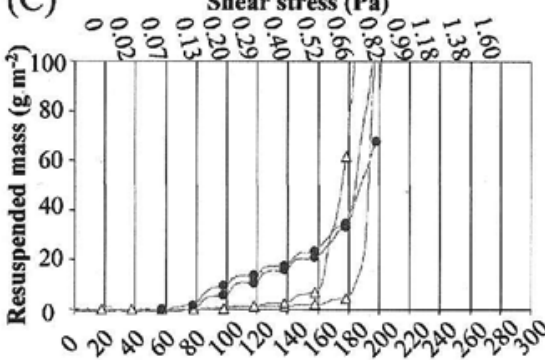

Time (min)

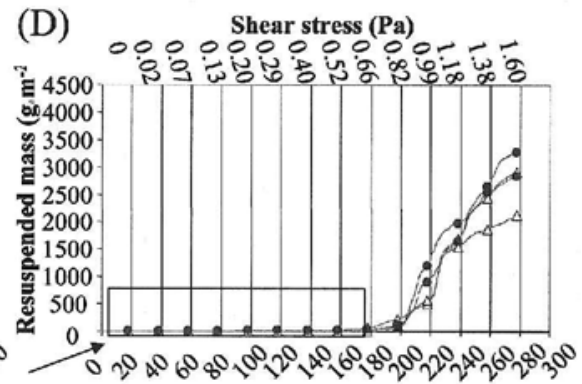

Time (min)

(F)

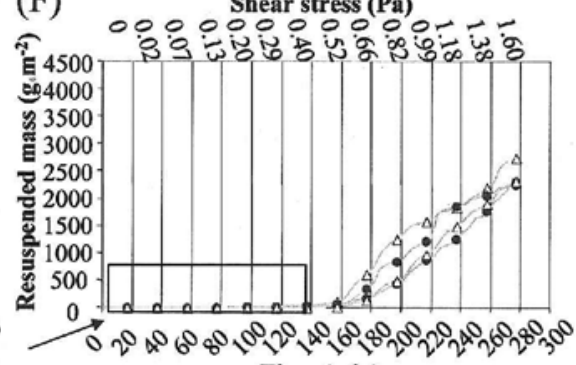

Time (min)

Figure 4. Measured time series of the eroded sediment mass $\left(M\right.$ in $\left.\mathrm{g} \mathrm{m}^{-2}\right)$ during the experiments. Subsets 1, 2 and 3 each had a different dry bulk sediment density (ca. 261, 236 and $190 \mathrm{~kg} \mathrm{~m}^{-3}$, respectively); experiments were performed both with Hydrobia ulvae (circles) and without snails (triangles). The biogenic fluff layer erosions (note that the $Y$-axis has been expanded to $100 \mathrm{~g} \mathrm{~m}^{-2}$ ) are shown in plots labeled A, C and E (for subsets 1, 2 and 3, respectively) and the corresponding subsequent bed erosions for the same subsets are depicted in plots $\mathrm{B}, \mathrm{D}$ and $\mathrm{F}$. 
observation). Resuspension curves without snails revealed that there were also small quantities of dislodged particles present on the bed that were not formed by snail activity. In the presence of snails, erosion decreased with dry density during the erosion of the fluff layer (Fig. 4A, 4C, 4E). This result was consistent with the observation that individual crawling rates and the quantity of tracks increase as sediment water content increases (Orvain and Sauriau, 2002).

Once resuspension of the fluff layer had occurred, there was no further influence of the snails on erosion patterns (Figs. 4B, 4D and 4F). Critical thresholds for bed erosion were high $(>0.9 \mathrm{~Pa})$ for the sediments with the highest dry density values (subset 1, Fig. 4B and Table 1). In this case, the scatter in critical shear stresses and erosion curves was large and the maximum eroded masses were between 2000 and $4000 \mathrm{~g} \mathrm{~m}^{-2}$. Bed failure took place earlier for more fluid sediments (subset 3, Fig. 4F and Table 1) and began at a critical bed shear stress from $0.52 \mathrm{~Pa}$ to $0.74 \mathrm{~Pa}$ and all the final eroded masses were ca. $2500 \mathrm{~g} \mathrm{~m}^{-2}$. Sediments with an intermediate density (subset 2, Fig. 4D and Table 1) also had intermediate values for critical thresholds (between 0.8 and $0.85 \mathrm{~Pa}$ ), erosion rates and their scattering magnitudes.

There was a continuous release of bed material whatever the applied shear stress and decreases in erosion rates within individual shear stress steps (Fig. 4F). This is consistent with the erosion of "placed" beds (Mehta and Partheniades, 1982; Mehta, 1988) or with the transitional erosion Type I/II reported by Amos et al. (1992, 1997), Houwing (1999) and Sanford and Maa (2001); fluff layer erosion is equivalent to the type IA erosion that has been described in situ by Amos et al. (1997) and Paterson and Black (1999). With respect to more consolidated sediments (Figs. 4B and 4D), the decrease in erosion as bed shear stress increased suggested that bed resistance increased, which was consistent with the measured dry density profiles of the test beds (Fig. 3).

\section{Model development}

\section{a. Conceptualization}

The primary objectives of this study were to develop a model for fluff layer erosion and subsequent erosion of the underlying sediment bed; thus it is required that the erosion threshold value can be varied vertically. The model was developed using a 3-step approach, summarized as follows: (1) analyses of fluff layer erosion were made using a deterministic, dimensionless model (Fig. 5A), (2) next analyses of bed erosion were made with a 1DV model (Fig. 5B), and (3) finally, the equations developed for fluff layer erosion were incorporated into the 1DV model (coupled model, Fig. 5C). A 1DV model for sediment erosion is justified since the sediment bed of the model is divided into vertical layers. The simulation of laboratory flume experiments did not require 1DV resolution in the water column as no signs of stratification were apparent.

$i$. The model for fluff layer erosion. At the beginning of the shear stress chronology ( $t=$ 0 ), the sediment quantity in the fluff layer $\left(A_{t=0}\right.$ in $\left.\mathrm{kg} \mathrm{m}^{-2}\right)$ is the sum of the sediment 
contained in the snail tracks $\left(A_{b t b}\right.$ in $\left.\mathrm{kg} \mathrm{m}^{-2}\right)$ plus other aggregates present on the bed when snails are absent $\left(A^{\prime}\right.$ in $\left.\mathrm{kg} \mathrm{m}^{-2}\right)$ :

$$
A_{t=0}=A_{b t b}+A^{\prime} .
$$

Conceptually, $A_{b t b}$ is the sediment quantity contained in the snail tracks. This mass can be evaluated as the product of the fraction of sediment area covered by snail tracks $(\phi$ expressed as a proportion), track height ( $h_{b t b}$ in $\mathrm{m}$ ) and the sediment concentration within the tracks $\left(\rho_{\text {fluff }}\right.$ in $\left.\mathrm{kg} \mathrm{m}^{-3}\right)$. The sediment area covered by snail tracks $(\phi)$ depends on the individual snail speed $(a)$, which varies with water content (Orvain and Sauriau, 2002). Track formation is, therefore, a time-dependent process; the surface covered by tracks reaches an asymptotic value when the sediment is fully bioturbated (Orvain and Sauriau, 2002). The general equations describing the combined effects of sediment water content and snail density on track formation were:

$$
A_{b t b}=h_{b t b} \rho_{\text {fluff }} \phi=h_{b t b} \rho_{\text {fluff }}\left(1-e^{-a n t}\right) \quad \text { and } \quad a=\frac{a_{0}}{1+e^{-\eta\left(W-W_{50}\right)}}
$$

where $h_{b t b}$ is the height of the tracks (m), $\rho_{\text {fluff }}$ the dry density within tracks $\left(\mathrm{kg} \mathrm{m}^{-3}\right), \phi$ is the fraction of sediment area covered by tracks, $n$ is the snail density (snail $\mathrm{m}^{-2}$ ), $t$ is the bioturbation time (in hours, $\mathrm{h}$ ), $a$ is the individual snail crawling rate $\left(\mathrm{m}^{2} \mathrm{~h}^{-1}\right.$ snail $\left.{ }^{-1}\right), a_{0}$ is the maximal crawling rate when $w \rightarrow \infty\left(\mathrm{m}^{2} \mathrm{~h}^{-1}\right.$ snail $\left.{ }^{-1}\right)$ and $\eta$ and $W_{50}$ are two empirical coefficients for the increase of crawling rate as a function of water content (Orvain and Sauriau, 2002). The density of crawling snails may vary during the simulated low-tide periods due to behavioral fluctuations (Orvain and Sauriau, 2002). In this study, the snail behavior has been cautiously interpreted and modeled and it has been demonstrated that the fluctuation in crawling snail density due to behavior (climbing, burying, floating, crawling) was not necessary to estimate the fraction of sediment area covered by tracks (which was the phenomenon responsible for the creation of the fluff layer by Hydrobia ulvae in the present study).

The height of tracks $\left(h_{b t b}\right)$ was assumed to increase with the water content since snail tracks were deeper in fluid layers:

$$
h_{b t b}=\psi \times W^{\theta}
$$

where $\psi$ and $\theta$ are two empirical parameters.

The quantity of aggregates $A^{\prime}\left(\mathrm{kg} \mathrm{m}^{-2}\right)$ detached from the sediment bed in the absence of snails, varied with water content (Fig. 3) according to the empirical law:

$$
A^{\prime}=\lambda_{1} W^{\lambda_{2}} .
$$

The fluff layer $\left(A_{t}\right)$ has its own low critical threshold $\left(\tau_{\text {fluff }}\right.$ in Pa). We assumed a linear relationship between erosion rate and the quantity $A_{t}$ that remained on the sediment bed at any given time. This was estimated with a modified Partheniades formulation (1965) as follows: 


$$
E_{\text {fluff }}=\alpha A_{t}\left(\frac{\tau_{f}}{\tau_{\text {fluff }}}-1\right) \text {, when }\left(\tau_{f}>\tau_{\text {fluff }}\right) \text { else } E_{\text {fluff }}=0
$$

where $E_{\text {fluff }}$ is the erosion flux from the fluff layer to the water column $\left(\mathrm{kg} \mathrm{m}^{-2} \mathrm{~s}^{-1}\right), \alpha$ is an erosion coefficient $\left(\mathrm{s}^{-1}\right)$ and $\left(\tau_{f} / \tau_{\text {fluff }}-1\right)$ represents the excess shear stress. The sediment volume remaining on the sediment bed $\left(A_{t}\right.$ in $\left.\mathrm{kg} \mathrm{m}^{-2}\right)$ varies in time as follows:

$$
\frac{d A_{t}}{d t}=-E_{\text {fluff }}
$$

This formulation has the advantage of accounting for the gradual shear-induced disruption of aggregates that we observed in our experiments and also generates a logistic pattern of erosion curves during the erosion process similar to those reported by Willows et al. (1998) in experiments with Macoma balthica and by Orvain (2002) for Hydrobia ulvae.

The reduction of erosion fluxes within each shear stress step can be explained by a spatial heterogeneity of resistance to erosion. The amount of mucus secreted by the snails may alter the erosion properties of their tracks; this is consistent with the experimental observation that some tracks are more easily eroded than others. Thus it is assumed that there is a variation in the critical shear stress relative to the quantity of sediment remaining in the fluff layer on the sediment bed $\left(A_{t}\right)$ :

$$
\tau_{\text {fluff }}=\tau_{\text {fluff }}^{\text {up }}+\delta \frac{A_{t=0}-A_{t}}{A_{t=0}} .
$$

At the initial erosion step, the critical shear stress for fluff layer erosion is equal to $\tau_{\text {fluff }}^{\text {up }}$ During fluff layer erosion, the aggregate quantity $\left(A_{t}\right)$ decreases and the critical shear stress for fluff layer erosion increases proportionally.

ii. The 1DV model for bed erosion. We used a 1DV sediment transport model of the SiAM series (Brenon and Le Hir, 1999; Le Hir et al., 2001). In this model, there is a continuous exchange of sediment between the bed and the water column since as soon as the sediment has entered the water column, part of the sediment particle population settles onto the sediment bed. The particles either remain deposited or are re-eroded, depending on the amount of excess shear stress (Fig. 5B). The sediment enters and leaves the water column according to the bed erosion and deposition terms $\left(E_{\text {bed }}\right.$ and $D$ in $\mathrm{kg} \mathrm{m}^{-2} \mathrm{~s}^{-1}$, respectively):

with $E_{\mathrm{bed}}=E_{0} \times \rho_{d}^{\gamma} \times\left(\frac{\tau_{f}}{\tau_{b}}-1\right) \quad$ and $\quad D=W_{S} \times S P M$ when $\tau_{f}>\tau_{b}$ else $E_{\mathrm{bed}}=0$

where $\tau_{b}$ is the critical shear stress $(\mathrm{Pa})$ for erosion, $E_{0}$ is the erosion coefficient $\left(\mathrm{kg} \mathrm{m}^{-2} \mathrm{~s}^{-1}\right),\left(\tau_{f} / \tau_{b}-1\right)$ represents the excess shear stress and $\gamma$ is an empirical coefficient having a power law as a function of dry density $\left(\rho_{d}\right.$ in $\left.\mathrm{kg} \mathrm{m}^{-3}\right)$. The bed erosion flux $E_{\text {bed }}\left(\mathrm{kg} \mathrm{m}^{-2} \mathrm{~s}^{-1}\right)$ is expressed according to a modified version of Partheniades' 
(1965) formulation, in which erosion rates increase with sediment dry density. This condition was necessary for a full reproduction of experimental data (Figs. 4B, 4D and 4F).

Due to the flume configuration, deposition is assumed to be spatially heterogeneous. While the sediment surface of the eroded zone is the surface of the flume test section $(S=$ $\left.0.36 \mathrm{~m}^{2}\right)$, the surface where deposited layers could accumulate is unknown $\left(S^{\prime}\right.$ in $\left.\mathrm{m}^{2}\right)$. Thus the following general equation was solved:

$$
\frac{d S P M}{d t}=E_{\mathrm{bed}} \times \frac{S}{V}-D \times \frac{S^{\prime}}{V}=E_{\mathrm{bed}} \times \frac{S}{V}-W_{s} \times S^{\prime} \times \frac{S P M}{V} .
$$

The flume contained a volume of seawater, $V$, equal to $1.16 \mathrm{~m}^{3}$. Both parameters $S^{\prime}$ and $W_{s}$ were unknown equation and their product $\left[W_{s} \times S^{\prime}\right]$ was found as a single parameter through minimization tests.

The sediment volume of the test bed was divided into layers, and vertical profiles of dry densities were estimated for each experiment (see Section $2 b$ ). The initial model layer thicknesses were identical (300 $\mu \mathrm{m}$ height); however, the surface layer thickness was allowed to change depending on erosion and deposition processes (see Fig. 5B). The critical shear stress $\left(\tau_{b}\right)$ depends on dry density $\left(\rho_{d}\right.$ in $\left.\mathrm{kg} \mathrm{m}^{-3}\right)$ according to a power law:

$$
\tau_{b}=c \rho_{d}^{d}
$$

where $c$ and $d$ are two empirical coefficients.

iii. The coupled $1 D V$ model. In addition to the sediment bed, the fluff layer is included in the 1DV model (Fig. 5C) to account for the sediment volume produced by the bioturbation activities $\left(A_{t=0}\right.$ in $\left.\mathrm{kg} \mathrm{m}^{-2}\right)$ of the snails. The thickness of the "fluff layer" cell may change in time ( $=A_{t} / \rho_{\text {fluff }}$ in $\mathrm{m}$ ) due to track formation (Eq. 2) and erosion (Eq. 5) during low tide and high tide, respectively.

The equations for sediment transport in the 1DV model were modified to incorporate into the balance both erosion terms ( $E_{\text {fluff }}$ and $E_{\text {bed }}$ ) already described (Eqs. 5 and 8):

$$
\frac{d S P M}{d t}=\left(E_{\text {fluff }}+E_{\text {bed }}\right) \times \frac{S}{V}-D \frac{S^{\prime}}{V} .
$$

As soon as the erosion of this sediment volume began, water column turbidity is produced and deposited layers are subject to re-erosion according to Eq. 8 .

\section{d. Model parameterization}

i. Fluff layer erosion. Fluff layer erosion (Fig. 4A, 4C and 4E) was estimated using the dimensionless model described in section $3 a(i)$ (Fig. 5A). In order to complete minimization tests of the parameters in Eqs. 4 through 7, a second data set of 20 experiments was pooled with the data presented here. The additional data set (Orvain, 2002) quantified the 
density effects of $H$. ulvae (evaluated at $0,1,000,5,000,10,000$ and 50,000 snails $\mathrm{m}^{-2}$ ) on fluff layer erosion using two higher sediment concentrations $\left(\rho_{d}\right.$ ranging between 420 $490 \mathrm{~kg} \mathrm{~m}^{-3}$ and $300-340 \mathrm{~kg} \mathrm{~m}^{-3}$ ). Experimental procedures were the same as the present study and, in these cases, no bed erosion was observed but only fluff layer erosion was observed (Figs. 9 and 10). These additional data were re-analyzed to evaluate the dependence on sediment water content and snail density using our new equations for fluff layer erosion.

First, parameters $\alpha$ and $A_{t=0}$ in Eqs. 5 through 7 were identified by minimization of the ordinary least squares (OLS) criterion, using a direct search (simplex of Nelder and Mead, 1965). One common value of $\alpha$ was estimated, while independent values of $A_{t=0}$ were adjusted for each experimental curve $(n=32)$. The critical shear stress for any bioturbated layers was fixed to $0.118 \mathrm{~Pa}$ (calculated from the thresholds shown in Figs. 4A, 4C and 4E) in both Eqs. 5 and 7; reasonable agreement $\left(r^{2}=0.98\right)$ was found between the variations in measured and computed eroded mass $(M)$. As expected, $A_{t=0}$ estimates for experiments with snails were greater than those without snails and also had a strong dependence on dry sediment density (Fig. 6); $A_{t=0}$ estimates reflected the combined effects of water content and snail density. The estimates of the amount of material in the fluff layer had a sigmoidal pattern as a function of sediment water content, and a von Bertalanffy (1938) curve as a function of snail density (Fig. 6).

Secondly, we tested Eqs. 1 through 4 for the dependence of $A_{t=0}$ on snail density and sediment water content in light of track formation mechanisms (Orvain and Sauriau, 2002). To achieve this, we minimized the parameters of fluff layer erosion functions using comparisons to the measured kinetics of eroded mass of the 32 experiments (Table 2). Based on observed crawled surfaces, Orvain and Sauriau (2002) developed a model simulating track formation at the sediment-water interface. This model allowed variations in crawling rates as a function of environmental factors to be simulated. In this study, four parameter sets were adjusted to describe the crawled surface in terms of bioturbation time, snail densities and water content under the following conditions: (1) low tide and day, (2) high tide and day, (3) low tide and night and (4) high tide and night. The second parameter set $\left(a_{0}, \eta\right.$ and $W_{50}$ in Eq. 2$)$ was used to reproduce the 5 hours of crawling activities with respect to the flume conditions (Table 2). All other parameters of Eqs. 1 through 4 (i.e. $\alpha$, $\left[\psi \times \rho_{\text {fluff }}\right], \theta, \lambda_{1}$ and $\lambda_{2}$ ) were minimized (Table 2). Functions for fluff layer erosion with their associated parameters were also incorporated into the $1 \mathrm{DV}$ model to evaluate the reliability of the present model.

Functions for fluff layer erosion with their associated parameters (Eqs. 1-4) can be used to provide an estimate of the proportion of the nonbiogenic aggregates to the sediment quantity in the fluff layer in the presence of snails by analyzing the variation of the ratio $A^{\prime} / A_{t=0} \times 100$ (Eqs. 1-4). This ratio increased with water content and in the 


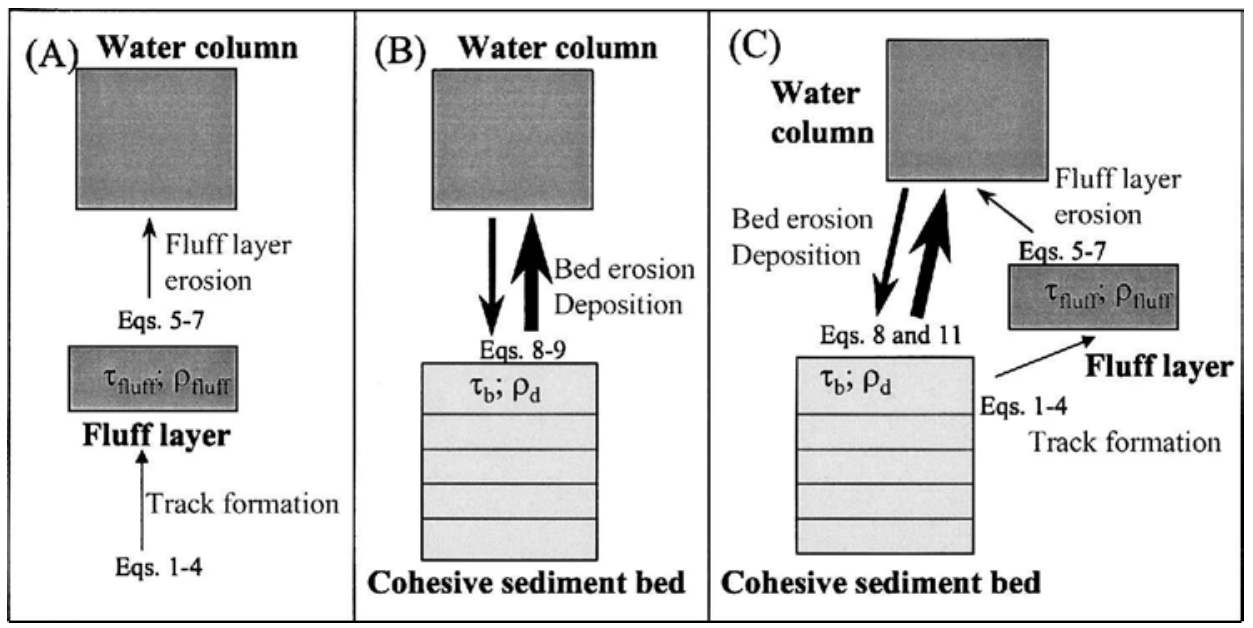

Figure 5. Schematic diagram of the particle exchange in the 3 models that were developed: (A) the dimensionless model simulating exchange between the "fluff layer" and the water column (i.e. initial stages of erosion and deposition), (B) the 1DV model without bioturbation where exchanges takes place between the top section of the sedimentary column and the water column and (C) the coupled model simulating particle exchange from the top section of the sedimentary column to the "fluff layer" (i.e. through the process of snail track formation), and from the "fluff layer" into the water column (i.e. the fluff layer erosion) and also between the top section of the sedimentary column and the water column (i.e. bed erosion and deposition). High erosion and deposition fluxes (i.e. Eq. 8 indicated by large arrows on diagrams) occur when $\tau_{f}>\tau_{b}$, while low erosion and deposition fluxes (i.e. Eq. 5 indicated by thin arrows on diagrams) occur when $\tau_{\text {fl uff }}<\tau_{f}<\tau_{b}$.

presence of 10,000 snails $\mathrm{m}^{-2}$, for instance, a maximal value of $3 \%$ was obtained. The fluff layer formation is thus essentially attributed to crawling activities of snails.

ii. Bed erosion. A reasonable agreement between variations in measured and computed eroded masses $(M)$ was obtained by fitting parameters of Eqs. 8 through 10 (i.e., $a_{\tau}, b_{\tau}$, $E_{0}, \alpha, \gamma$ and $W_{s}$ ). No improvement in fit was gained by including the probability of deposited material remaining on the sediment bed $\left(\tau_{f} / \tau_{c d}\right.$ that is used classically in mathematical models of mud transport; see e.g. Ariathurai and Krone, 1976; van der Ham and Winterwerp, 2001). Computed eroded masses realistically accounted for both the effects of sediment concentration on critical shear stress and the erosion rate with acceptable adjustments $\left(r^{2}=0.73\right.$; Fig. 7). Adjustments were improved substantially with the erosion function we used (Eq. 8) as compared to the classical Partheniades formulation (where erosion rates are not related to dry density).

The experiments with the most concentrated sediments (subset 1) did not fit as well as those from subsets 2 and 3 (Fig. 7). Consequently, results from subset 1 were responsible 


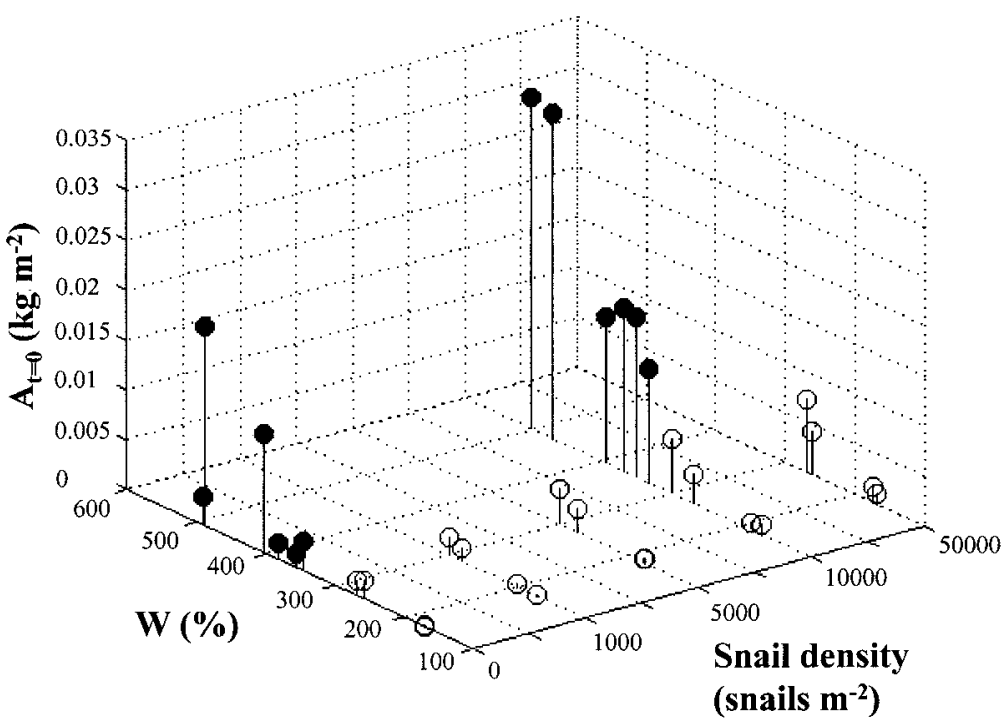

Figure 6. $A_{t=0}$ estimates (i.e. quantity of sediment in the fluff layer) obtained by minimization of Eqs. 5 through 7 as a function of sediment water content (as \% water) and snail density (as snails $\mathrm{m}^{-2}$ ). The minimization approach was performed on data presented in the current study (filled circles) and included a second data set discussed in Orvain (2002) that has been reanalyzed here (open circles).

for a substantial part of the scatter in the plot of model prediction against observed masses. This is due to the observed high variations in critical thresholds, irrespective of the scatter in measured sediment density, in this case (Subset 1 in Table 1).

iii. The coupled model. Fluff layer erosion and bed erosion functions were coupled within the 1DV model and all parameters of equations for track formation, track erosion and bed erosion were used (Table 2). The model consistently reproduced the sequence of phases of fluff layer and bed erosion, as observed in the experiments (Fig. 4). Good adjustments to the observed fluff layer erosion phase were obtained (Fig. 8). The dependence of erosion rates on snail density and water content was correctly reproduced by functions for fluff layer erosion, when compared to results obtained with fluid sediments (Fig. 8). The reduction in eroded mass within each shear stress step was fairly well reproduced by incorporating the varying resistance of the fluff layer to erosion (Eq. 7).

The model also consistently estimated the effects of snail density on the fluff layer erosion rates of more concentrated sediments (Figs. 9 and 10). This result suggests that variations in erosion rates of the fluff layer can be attributed to the effects of snail bioturbation (track formation) on the surface sediments. 
Table 2. Summary of equations and parameters used in the sediment transport 1DV model with Hydrobia ulvae bioturbation.

\begin{tabular}{|c|c|c|c|c|}
\hline Acronyms & Value & Unit & Description & Origin \\
\hline \multicolumn{5}{|c|}{ FORCING VARIABLES } \\
\hline$\sigma_{f}$ & Function of time (step-by-step) & $\mathrm{Pa}$ & Bed share stress & Measured \\
\hline$n$ & Function of experiment & Snail $\mathrm{m}^{-2}$ & Hydrobia ulvae density & Measured \\
\hline$\rho_{d}$ & Function of experiment & $\mathrm{kg} \mathrm{m}^{-3}$ & Sediment dry density & Measured \\
\hline$w$ & Derived from $\rho_{d}$ & $\%$ & Sediment moisture content & Measured \\
\hline \multicolumn{5}{|c|}{ STATE VARIABLES } \\
\hline$M$ & $\frac{d M}{d t}=E_{\text {fluff }}+E_{\text {bed }}-D$ & $\mathrm{~kg} \mathrm{~m}^{-2}$ & Eroded mass per unit area & \\
\hline$A_{t}$ & $\frac{d A_{t}}{d t}=-E_{\mathrm{fluff}}$ & $\mathrm{kg} \mathrm{m}^{-2}$ & Aggregate quantity in fluff layer & \\
\hline
\end{tabular}

BIOGENIC FLUFF LAYER EROSION FUNCTIONS AND COEFFICIENTS

Crawling activity: $a=\frac{a_{0}}{1+e^{-\eta\left(W-W_{50}\right)}}$
$\begin{array}{ll}a_{\mathrm{O}} & 42.2 \times 10^{-6} \\ \eta & 51.8\end{array}$
$\mathrm{m}^{2}$ snail $^{-1} \mathrm{~h}^{-1}$ Maximum individual crawling rate
Orvain and Sauriau (2002)
Rate of increase of crawling rate as a
Orvain and Sauriau (2002)
$W_{50} \quad 199.8$
$\% \quad W$-dependent parameter
Orvain and Sauriau (2002)

Track formation: $A_{b t b}=h_{b t b} \rho_{\text {fluff }}\left(1-e^{- \text {ant }}\right)$ and $h_{b t b}=\psi \times W^{\theta}$

$\begin{array}{ccccc}\psi \times \rho_{\text {fluff }} & 6.16 \times 10^{-8} & \mathrm{~kg} \mathrm{~m}^{-2} & \begin{array}{c}\text { Maximum sediment quantity } \\ \text { reworked by Hydrobia ulvae }\end{array} & \text { minimized } \\ \theta & 2.424 & - & W \text {-dependent coefficient of track height } & \text { minimized }\end{array}$

Fluff layer formation: $A_{t=\mathbf{O}}=A_{b r b}+\lambda_{1} W^{\lambda_{2}}$
$\lambda_{1}$
$6.386 \times 10^{-16}$
No unit
Parameter for aggregates when $n=0$
minimized
$\lambda_{2} \quad 4.556$
No unit
Parameter for aggregates when $n=0$
minimized

Critical shear stress for fluff layer erosion: $\tau_{\text {fluff }}=\tau_{\text {fluff }}^{\text {up }}+\delta \frac{A_{t=0}-A_{t}}{A_{t=0}}$
$\tau_{\text {fluff }}^{\text {LP }} \quad 0.118$
$\delta \quad 0.744$
$\mathrm{Pa} \quad \tau_{\text {fluff }}$ at sediment-water interface
Pa Rate of increase of $\tau_{\text {fluff }}$

fixed

minimized

Fluff layer erosion: $E_{\text {fluff }}=\alpha \times A_{t} \times\left(\frac{\tau_{f}}{\tau_{\text {fluff }}}-1\right)$ when $\tau_{f}>\tau_{\text {fluff }}$, else $E_{\text {fluff }}=0$
$\alpha$
$1.525 \times 10^{-4}$
$\mathrm{s}^{-1}$
Erosion coefficient

minimized

\section{GENERAL BED EROSION FUNCTIONS AND COEFFICIENTS}

Critical shear stress for bed erosion: $\tau_{b}=a_{\tau} \times \rho_{d}^{b_{\tau}}$
$a_{\tau}$
$1.26 \times 10^{-6}$
$\mathrm{Pa}$
$\rho_{d}$ dependence coefficient
minimized
$b_{\tau}$
2.502
$-$
$\rho_{d}$ exponent coefficient
minimized

Bed erosion: $E_{\mathrm{bed}}=E_{0} \times \rho_{d}^{\gamma} \times\left(\frac{\tau_{f}}{\tau_{b}}-1\right)$ when $\tau_{f}>\tau_{b}$, else $E_{\mathrm{bed}}=0$
$E_{\mathrm{O}}$
$1.06 \times 10^{-12}$
$\mathrm{kg} \mathrm{m}^{-2} \mathrm{~s}^{-1}$
Erosion coefficient
minimized
$\gamma$
3.984
- $\quad \rho_{d}$ exponent coefficient
minimized

Deposition: $D=W_{s} \times M \times \frac{S}{V}$

$\begin{array}{cc}{\left[W_{s} \times S^{\prime}\right]} & 1.071 .10^{-3} \\ S & 0.33 \\ V & 1.16\end{array}$
$\left[\mathrm{m} \mathrm{s}^{-1} \times \mathrm{m}^{2}\right] \quad[$ Settling velocity $\times$ deposition surface]

minimized

$\begin{array}{lll}\mathrm{m}^{2} & \text { Test section surface } & \text { measured } \\ \mathrm{m}^{3} & \text { Flume volume } & \text { measured }\end{array}$

$\begin{array}{lll}\mathrm{m}^{2} & \text { Test section surface } & \text { measured } \\ \mathrm{m}^{3} & \text { Flume volume } & \text { measured }\end{array}$ 
(A)

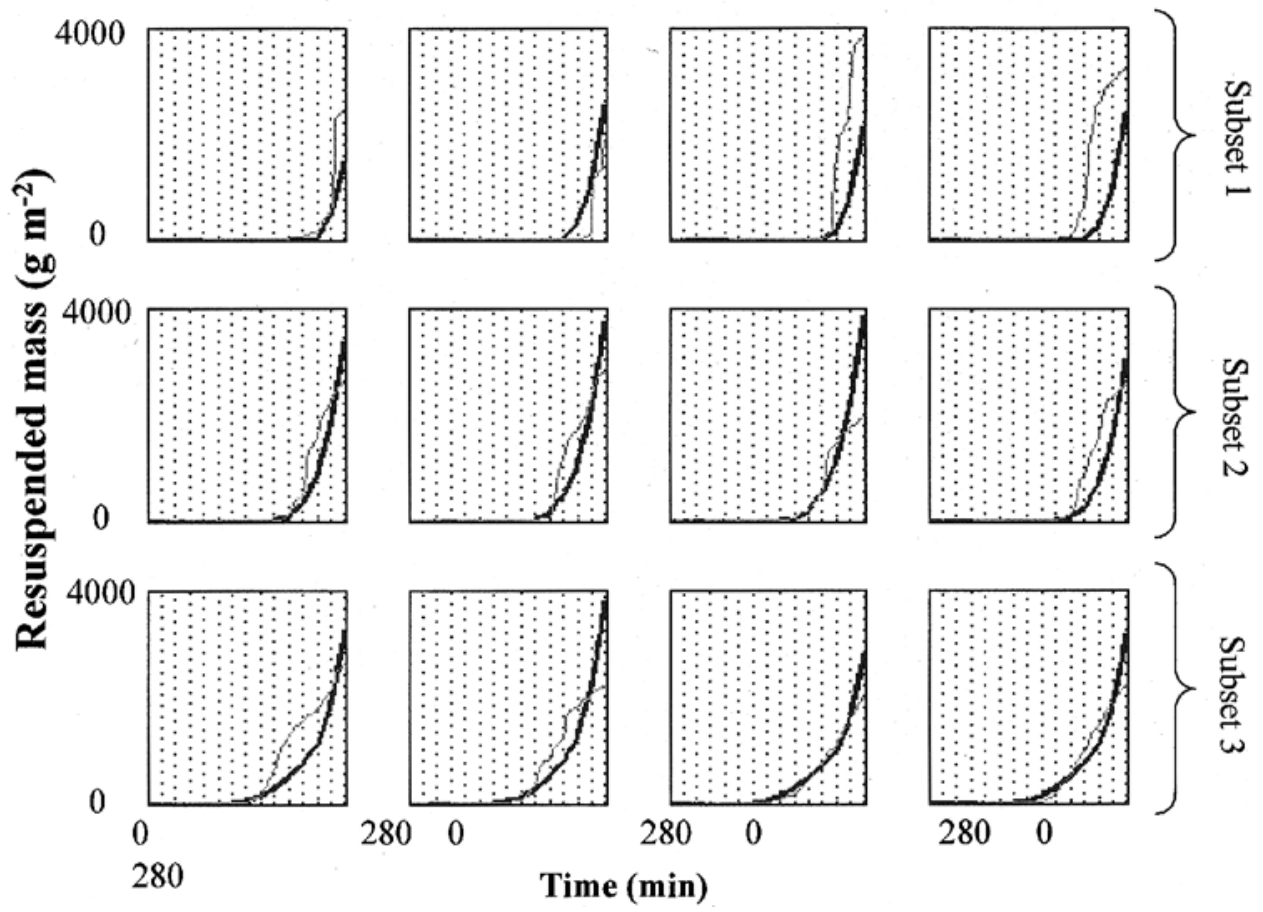

(B)

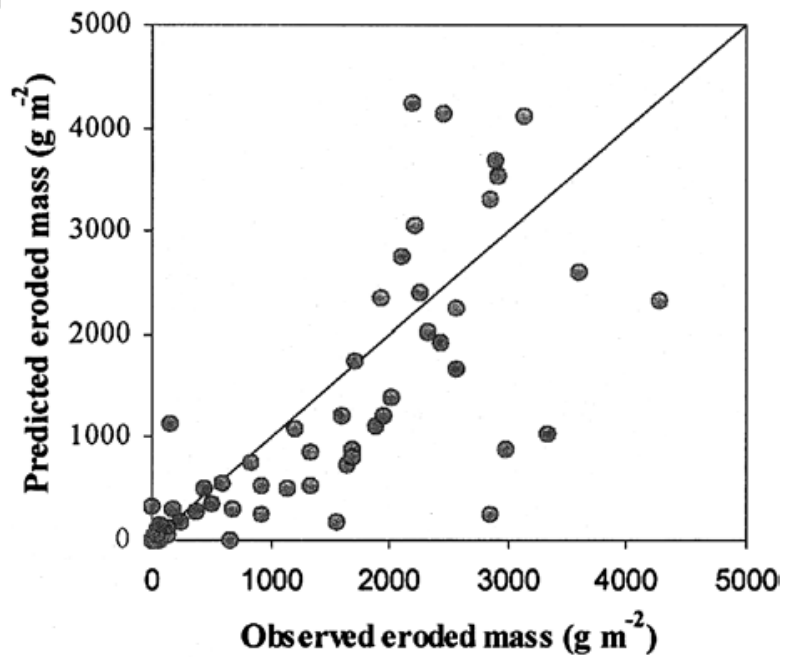

Figure 7. Comparison between the model predictions for bed erosion and the time series of eroded mass for the 12 experiments conducted with mean dry densities of 261 (subset 1), 236 (subset 2) and $190 \mathrm{~kg} \mathrm{~m}^{-3}$ (subset 3). (A) Model results were computed by considering the estimated dry density profile of each experiment. (B) The relationship between observed and predicted data of bed erosion was not significantly different from the theoreticalmodel, $Y=X\left(r^{2}=0.735 ; F_{1,166}=460 ; P<0.001\right)$. 

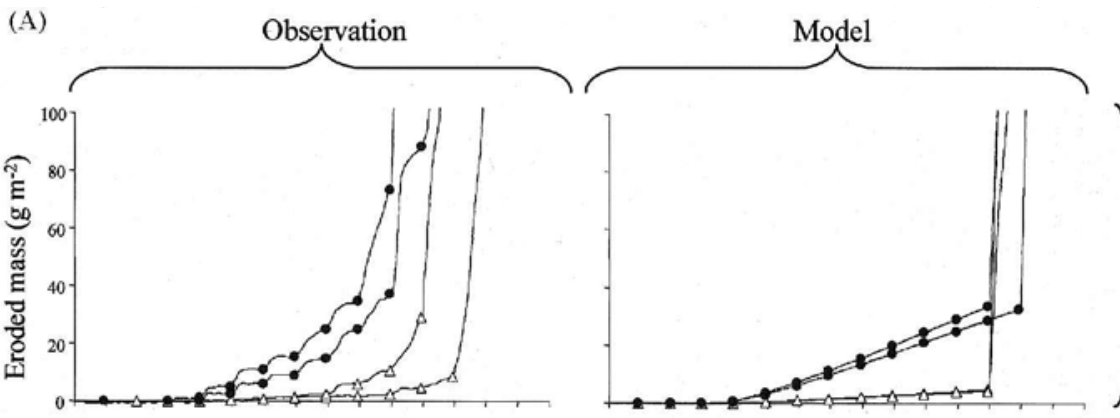

Subset 1
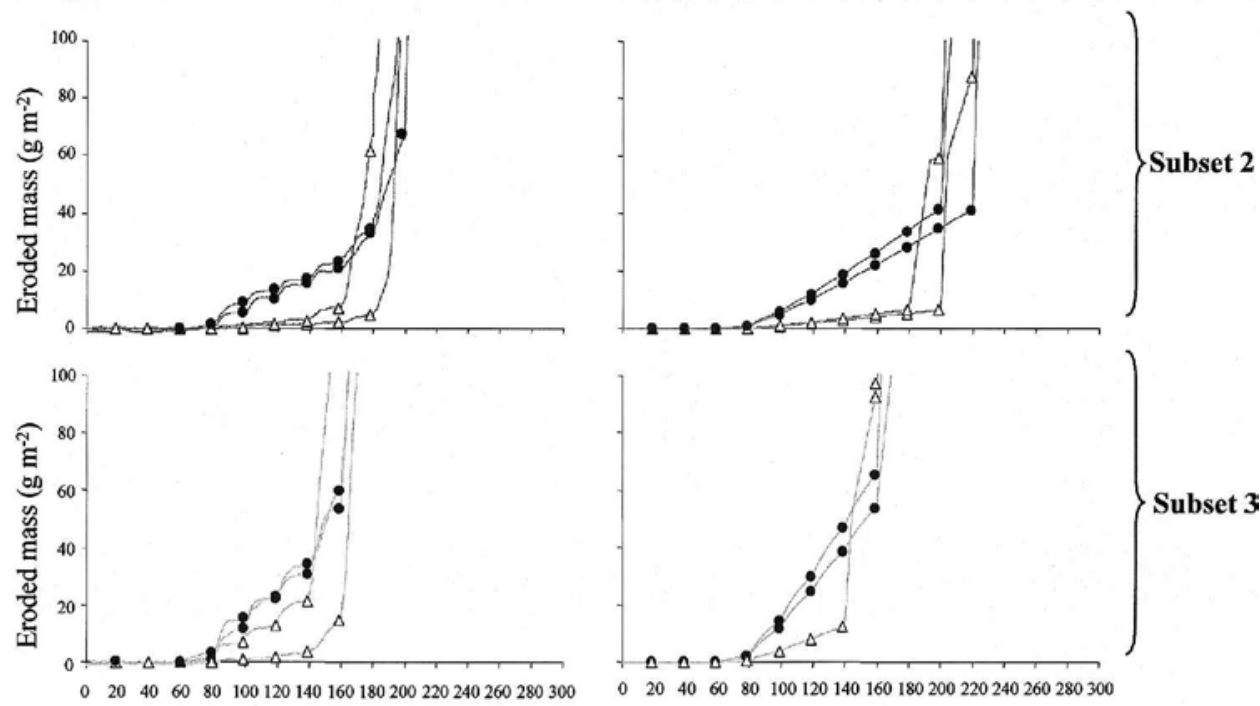

Time (min)

Time (min)

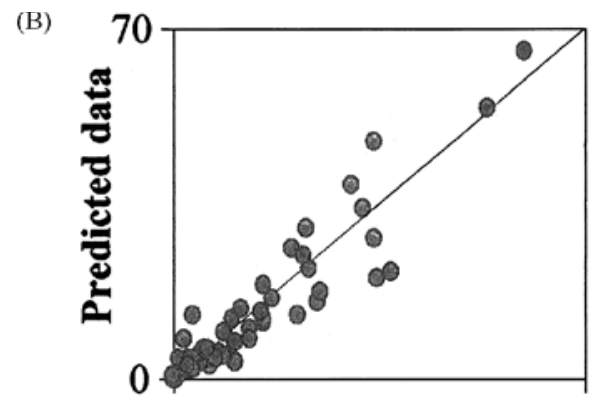

\section{Observed data 70}

Figure 8. (A) Comparison between model prediction (diagrams on the right) and data (diagrams on the left) of the 12 experiments. The experiments with and without Hydrobia ulvae are represented by circles and triangles, respectively, on the curves. (B) The relationship between the model prediction and the observations that were calculated on the basis of averaged 80-data of each shear stress step, was not significantly different from $Y=X\left(r^{2}=0.901 ; F_{1,106}=973 ; P<0.001\right)$. 

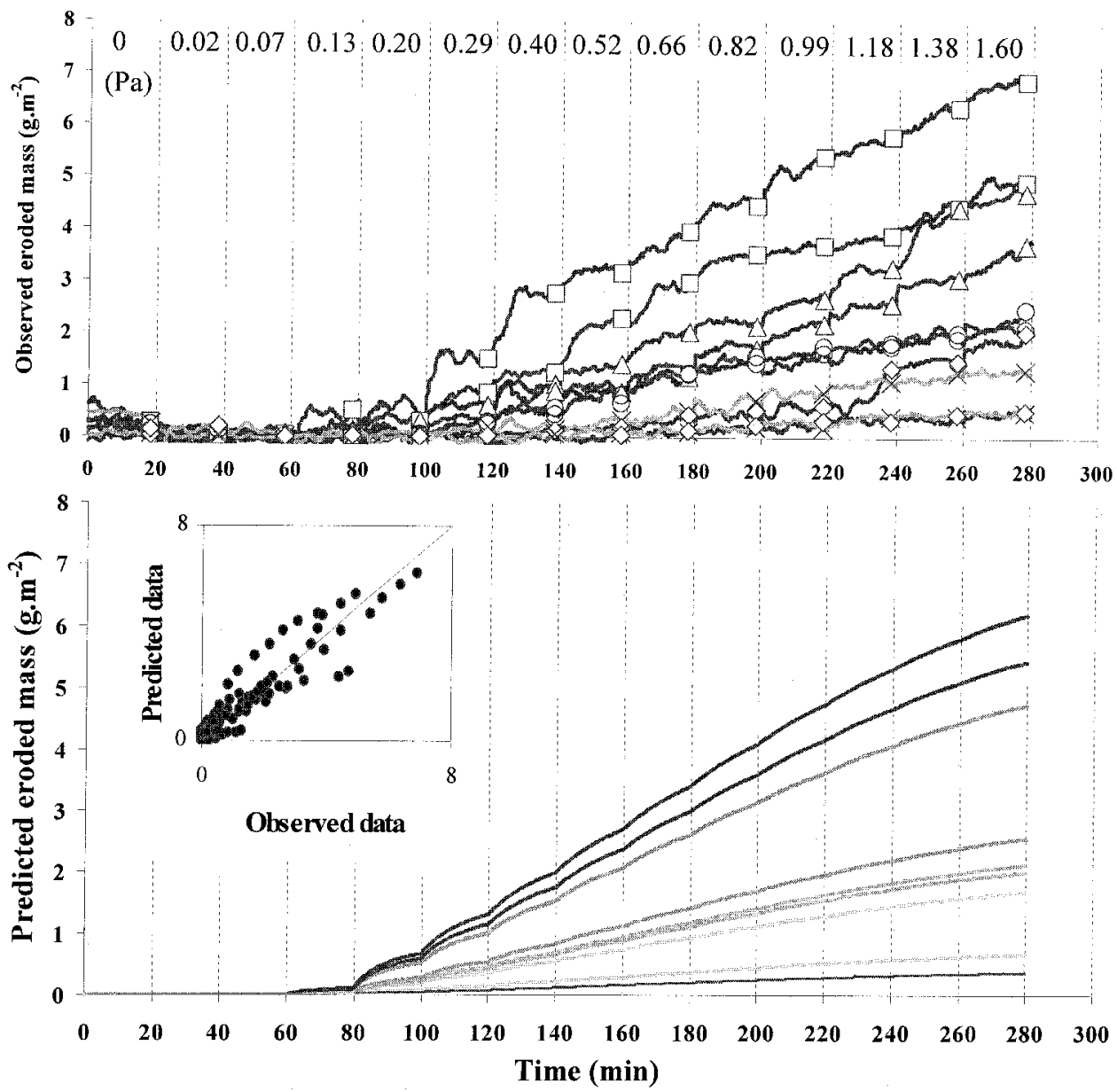

Figure 9. Comparison between the time series plots of experimental (A) and computed (B) sediment eroded mass per unit area $\left(M\right.$ in $\left.\mathrm{g} \mathrm{m}^{-2}\right)$ in response to shear stress increment on consolidated sediments $\left(\rho_{d}=468.8 \pm 20.3 \mathrm{~kg} \mathrm{~m}^{-3}\right)$ from experiments that were described by Orvain (2002). The grey lines on diagrams (A) and (B) represent controls without Hydrobia (crosses) and dark lines represent experiments with 1,000,5,000, 10,000 and 50,000 snails $\mathrm{m}^{-2}$ (symbols are diamonds, circles, triangles and squares for each density, respectively). (C) The relationship between the model prediction and the observations that were calculated on the basis of averaged 80-data of each shear stress step was not significantly different from $Y=X\left(r^{2}=0.942\right.$; $\left.F_{1,166}=1299 ; P<0.001\right)$.

\section{Discussion and conclusions}

a. The reliability and the interest of the model

Models of sediment transport that include bioturbation effects are developed with the goal of extrapolating the results to field conditions (Wood and Widdows, 2002). The applicability of these models are constrained by having to: 

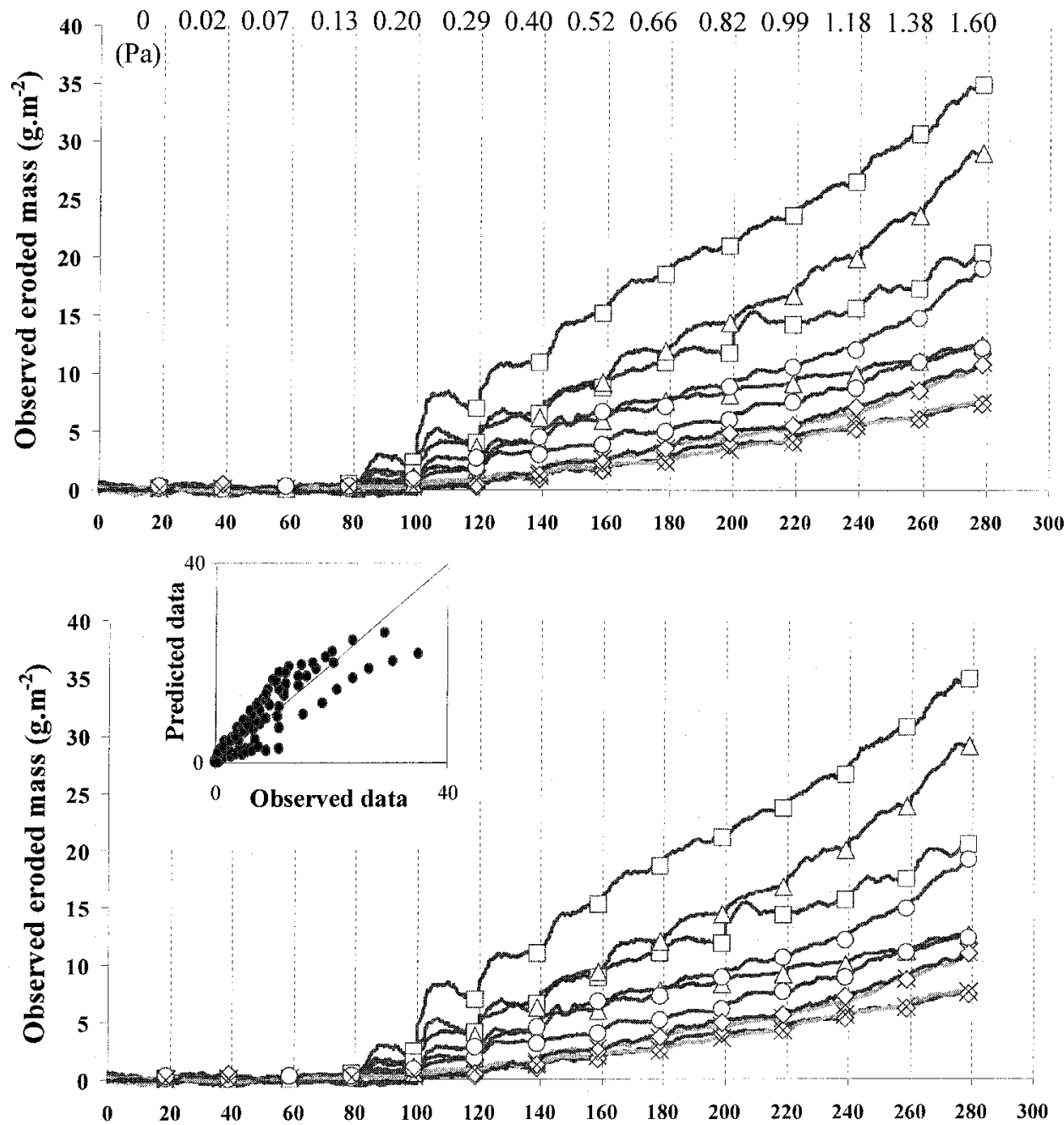

Figure 10. Comparison between the time series plots of experimental (A) and computed (B) sediment eroded mass per unit area $\left(M\right.$ in $\left.\mathrm{g} \mathrm{m}^{-2}\right)$ in response to shear stress increment on consolidated sediments $\left(\rho_{d}=318.9 \pm 15.6 \mathrm{~kg} \mathrm{~m}^{-3}\right)$ from experiments that were described by Orvain (2002). The grey lines on diagrams $\mathrm{A}$ and $\mathrm{B}$ represent controls without Hydrobia (crosses) and dark lines represent experiments with 1,000,5,000,10,000 and 50,000 snails $\mathrm{m}^{-2}$ (symbols are diamonds, circles, triangles and squares for each density, respectively).(C) The relationship between the model prediction and the observations, that were calculated on the basis of averaged 80-data of each shear stress step, was not significantly different from $Y=X\left(r^{2}=0.825 ; F_{1,166}=785 ; P<0.001\right)$.

(1) use a reduced set of parameters;

(2) assess effects under a wide and often largely unknown set of field conditions (e.g. varying water contents, tidal forcing, species and spatio-temporal variations in macrobenthic populations); 
(3) be compatible with sediment bed erosion functions that take into account the effect of sediment consolidation status on $\tau_{b}$;

(4) make predictions of erosion on the basis of biological and sedimentological variables that can be easily measured;

(5) account for hydrodynamic forcings that could include the combined effects of currents, waves, their nonlinear interactions and bed roughness.

The present model is robust with respect to these five conditions:

(1) The model uses a set of four minimized parameters for fluff layer erosion ( $\alpha$, $[\psi \times$ $\left.\rho_{\text {fluff }}\right]$ and $\left.\theta\right)$ and a set of three fixed parameters $\left(a_{0}, \eta\right.$ and $\left.W_{50}\right)$, which was obtained from the development of a model for crawling behavior of snails (Orvain and Sauriau, 2002). This set of three parameters can be modified as a function of light and water coverage conditions. The contribution of the nonbiogenic aggregates to the fluff layer have been demonstrated to be negligible and should be different in nature than in our laboratory study. The function for this nonbiogenic fluff layer function (with associated parameters $\lambda_{1}$ and $\lambda_{2}$ ) will thus not be considered in further model development simulating field conditions;

(2) The model for fluff layer reliably reproduced the erosion of a wide range of flume experiments with a single set of parameters. The model is based on the track formation mechanisms and simulates the snail density and water content dependence of fluff layer erosion rates within the range of values that can be encountered in the field. Crawling rates also depend on the microphytobenthic populations, which is the snail's prey. The effect of microphytobenthic biomass can be included in the track formation equations as well as the light and water coverage conditions (Orvain and Sauriau, 2002).

(3) The model allows us to simulate the effects of benthic organisms on fluff layer erodibility without affecting the bed erosion parameters, so that the effect of physical factors on bed erodibility (such as the dependence of $\tau_{c r}$ on sediment concentration or consolidation processes) can be taken into account as usual,

(4) Snail densities, bed shear stress and water contents are the forcing variables of the model. The variations in snail density are available from studies on population dynamics and spatial patterns of this species (Haubois et al., 2002). Values of bed shear stress are available from a hydrodynamics model in the Marennes-Oléron Bay (Le Hir et al., 2000). This model also simulates consolidation processes, hence providing estimates of sediment water content as a function of emersion time.

(5) Both erosion functions (for fluff layer and sediment bed) depend on bed shear stress, hence allowing consideration of wave effects or bed roughness effects rather than current velocity. 
We made several simplifying assumptions in the model that proved reasonable: (1) the assumed dependence of erosion rates on the quantity of fluff layer during the erosion process (Eq. 5 and 6) allowed the decrease in erosion rates at higher shear stresses which was observed on consolidated sediments (Figs. 9 and 10) to be reproduced; (2) assuming a spatial heterogeneity in the resistance of tracks (Eq. 7) allowed the observed decrease in erosion rates within shear stress steps (Figs. 8, 9 and 10) to be recreated, and (3) considering that the effects of a bioturbated (or crawled) surface (Eq. 2) would be to mediate the effects of snail density and sediment water content, reproduced the observed differences between experimental conditions (Figs. 8,9 and 10).

The main advantage of our approach is that the same parameter sets can be used to simulate erosion kinetics, even when sediments have different consolidation states and histories (Figs. 8, 9 and 10). The bed and fluff layer erosions are thus not affected similarly by water content variations. This has not been possible with other models, such as a modified version of Willow's model (Willows et al., 1998 modified by Orvain, 2002). Thus, to the knowledge of the authors, this model is the first that evaluates the contribution of biological versus physical factors on bed erodibility.

The dependence of fluff layer erosion rates on snail density and water content has been well reproduced by considering the effects of these two variables on track formation by snails. This result provides an argument demonstrating that the main process controlling the effect of Hydrobia ulvae activities on bed erodibility is the track formation process. The main fraction of the fluff layer that is produced by $H$. ulvae can thus be ascribed to tracks.

The predictive ability of the model could be limited since only a narrow temporal sequence of the complete tidal cycle (i.e. diurnal emersion phases) is simulated in the present version. However, the influence of environmental factors on crawled surfaces was investigated under a wider variety of environmental conditions (Orvain and Sauriau, $2002)$, so that the 3-parameter sets of each system $\left(a_{0}, \eta\right.$ and $\left.W_{50}\right)$ can be used in the 1DV coupled model. Such model implementations should provide realistic simulations of snail bioturbation effects over the complete tidal sequence. Nevertheless, the present model should be validated by comparison to additional flume experiments conducted under different conditions of light and water coverage.

One of the unique features of the functions for fluff layer consists of the ability to simulate a decrease in erosion rate without requiring a deposition flux. This was achieved by considering that the resistance of individual tracks to erosion is heterogeneous on sediment surface. The decrease in fluff layer erosion rate was thus a function of the variable critical threshold for fluff layer erosion and realistic erosion patterns could not be simulated without imposing some level of heterogeneity in the model. Concerning the bed erosion, a vertical variation of the critical shear stress was assessed in relation to the sediment density profile and this implies a reduction in erosion rate due to the consolidation status. In addition, a fraction of the total eroded particles was 
allowed to settle on the sediment bed. Very low critical thresholds were attributed to the re-erosion of these deposited particles. In the model, deposition is thus assessed as a settling flux that occurs at the same time as erosion (fluff layer erosion as well as bed erosion). We actually had two possibilities: (1) either simulating a deposition term from the water column to the fluff layer cell or (2) simulating a deposition term from the water column to the surface sediment layer. According to the case, the re-erosion of deposited particles could be calculated using either fluff layer or bed erosion functions. We made the second choice to avoid the production of a biogenic fluff layer in the absence of snails and to avoid any numerical artefact in the calculation of the deposition term due to the inclusion of biological effects. The modeling strategy allows bed erosion and deposition functions to be formulated as is usually seen in sediment transport models in the absence of snails.

\section{b. Destabilizing effects by deposit-feeders}

Bioturbation effects by Hydrobia ulvae on the surface sediments are limited in our flume experiments to the creation of a fluff layer, and not the effects of changes in bed roughness. The tracks themselves do not affect bed roughness and the underlying bed erosion properties do not depend on snail densities. Such fragile fluff layers cannot produce obstacles which affect the general bed roughness. Irregularities due to tracks may induce a modification of the surface roughness but this effect is limited to a very slight temporal window of erosion sequence. This effect can perhaps contribute to the low threshold for fluff layer erosion that we have reported.

However, the shells of the snails may produce significant and robust obstacles during a natural tidal cycle. These animals have the ability to resist very strong currents by adherence (visual observation). We controlled the bed roughness in our experiments by letting the animals escape from test section before applying the currents. We assume that under field conditions, the influence of snail shells on bed roughness is another potential process and should be incorporated into sediment transport models as data become available. The expected effects of this roughness modification by snail shells are high since it affects bed erosion.

Hydrobia ulvae is a very motile species which dominates macrobenthic populations of many bays and estuaries over large geographic regions. Widdows et al. (2000a) have reported from in situ measurements on the Molenplaat (Westerschelde, Netherlands) that $H$. ulvae appears to destabilize sediment, but to a lesser extent than other bivalves (such as Macoma balthica or Scrobicularia plana). Directly comparing H. ulvae and M. balthica effects using Willows' model (Orvain, 2002) confirmed this observation. Andersen (2001) has demonstrated that at sites dominated by H. ulvae erosion rates were positively correlated with the snail faecal pellet content of the surface sediments. Their wide distribution on European intertidal mudflats suggests the snails' activities may have an appreciable effect on sediment erosion properties. In the MarennesOléron Bay (France), where this species is dominant, the effects of H. ulvae on 
sediment transport could be simulated by incorporating recent data on the spatiotemporal dynamics of this organism (Haubois et al., 2002). The main interest of the model is that it can be used to analyze the contribution of biological factors in the resuspension of natural sediments, since physical processes (e.g. deposition, consolidation and bed erosion) and their impact on sediment dynamics are also considered. Future studies will investigate the impact of the bioturbation by Hydrobia ulvae versus physical factors on the in situ sediment budget of mudflats in the Marennes-Oléron Bay by applying this model on a large scale.

The upper layers of the marine sediments are mixed, bulldozed and loosened by many organisms and, especially by deposit-feeders, which displace large quantities of surface material during the course of their foraging activities (Rhoads and Young, 1970; Jumars and Nowell, 1984; Hall, 1994; Paterson and Black, 1999; Willows et al., 1998). Concerning Hydrobia ulvae, all these activities contribute to the creation of a fluff layer on the surface, which is a complex assemblage of flocs, micro-organisms, mucous tracks, pellets and sediment (Blanchard et al., 1997; Andersen et al., 2002). All the material in the fluff layer is not likely to behave the same way in terms of resuspension and this could explain the heterogeneity in fluff layer resistance observed in this study, the flocs, mucous tracks and micro-organisms being able to resuspend first while faecal pellets are likely to be more resistant to erosion. Faecal pellets are robust elements which are resistant to bacterial and physical breakdown. A series of studies (Andersen, 2001; Andersen and Pejrup, 2002; Andersen et al., 2002) have indicated that the re-deposition and accumulation of faecal pellets probably enhances the role of pelletization in the field in contrast with laboratory experimental conditions. In future studies, the quality of the sediment in the fluff layer should thus be taken into account to model the fluff layer resuspension and its impact on sediment transport in the field.

Grouping deposit-feeders into functional groups has been demonstrated to be a reliable method in understanding bioturbation effects of different species (Pearson, 2001). The omnipresence of deposit-feeder populations at the sediment-water interface in intertidal systems (Herman et al., 1999) and a specific functional group of bioturbator ("fluff layer creator") can be associated with this process. In that sense, Hydrobia ulvae can be considered as a member of this functional group.

While models predicting the potential effects of bioturbation on sediment mixing and nutrient distribution in sediments have been the subject of increasing investigation (François et al., 1997, 2002; Dauwe et al., 1998; Boudreau, 2001; Pearson, 2001), models predicting sediment stability and erosion on the basis of biological benthic processes remain relatively rare (Willows et al., 1998; Orvain, 2002). The model and approach presented in this communication represent a methodology that can be used for investigating the effects of other representative members of the "fluff layer creators" group, and therefore also represent a potentially effective means of analyzing not only the contribution 
of $H$. ulvae to fluff layer formation, but also for exploring interspecific interactions in the bioturbated environment.

Acknowledgments. The IFREMER and Regional Council of Poitou-Charentes supported the study with a doctoral grant awarded to F.O. We also thank two anonymous referees who made helpful comments on earlier drafts.

\section{REFERENCES}

Amos, C. L., T. Feeney, T. F. Sutherland and J. L. Luternauer. 1997. The stability of fine-grained sediments from the Fraser River Delta. Estuar. Coast. Shelf Sci., 45, 507-524.

Amos, C. L., J. Grant, G. R. Daborn and K. Black. 1992. Sea carousel-a benthic, annular flume. Estuar. Coast. Shelf Sci., 34, 557-577.

Amos, C. L., N. A. Van Wagoner and G. R. Daborn. 1988. The influence of subaerial exposure on the bulk properties of fine-grained intertidal sediment from Minas Basin, Bay of Fundy. Estuar. Coast. Shelf Sci., 27, 1-13.

Andersen, T. J. 2001. Seasonal variation in erodability of two temperate, microtidal mudflats. Estuar. Coast. Shelf Sci., 53, 1-12.

Andersen, T. J., K. T. Jensen, L. Lund-Hansen, K. N. Mouritsen, and M. Pejrup. 2002. Enhanced erodability of fine-grained marine sediments by Hydrobia ulvae. J. Sea Res., 48, 51-58.

Andersen, T. J. and M. Pejrup. 2002. Biological mediation of the settling velocity of bed material eroded from an intertidal mudflat. Estuar. Coast. Shelf Sci., 54, 737-746.

Ariathurai, R. and R. B. Krone. 1976. Finite element model for cohesive sediment transport. J. Hydraul. Div. ASCE, 102, 323-338.

Bassoulet, P., P. Le Hir, D. Gouleau and S. Robert. 2000. Sediment transport over an intertidal mudflat: field investigations and estimation of fluxes within the "Baie de Marennes-Oléron" (France). Cont. Shelf Res., 20, 1635-1653.

Bertalanffy von, L. 1938. A quantitative theory of organic growth. Human Biol., 10, 181-213.

Blanchard, G. F., P.-G. Sauriau, V. Cariou-LeGall, D. Gouleau, M. J. Garet and F. Olivier. 1997. Kinetics of tidal resuspension of microbiota: testing the effects of sediment cohesiveness and bioturbation using flume experiments. Mar. Ecol. Prog. Ser., 151, 17-25.

Boudreau, B. P. 2001. A one-dimensional model for bed-boundary layer particle exchange. J. Mar. Syst., 11, 279-303.

Brenon, I. and P. Le Hir. 1999. Modelling the turbidity maximum in the Seine Estuary (France): identification of formation processes. Estuar. Coast. Shelf Sci., 49, 525-544.

Dauwe, B., P. M. J. Herman and C. H. R. Heip. 1998. Community structure and bioturbation potential of macrofauna at four North Sea stations with contrasting food supply. Mar. Ecol. Prog. Ser., 173, 67-83.

François, F., M. Gérino, G. Stora, J.-P. Durbec and J.-C. Poggiale. 2002. Functional approach to sediment reworking by gallery-forming macrobenthic organisms: modeling and application with the polychaete Nereis diversicolor. Mar. Ecol. Prog. Ser., 229, 127-136.

François, F., J.-C. Poggiale, J.-P. Durbec and G. Stora. 1997. A new approach for the modelling of sediment reworking induced by a macrobenthic community. Acta Biotheor., 45, 295-319.

Gouleau, D., J. M. Jouanneau, O. Weber and P. G. Sauriau. 2000. Short- and long-term sedimentation on Montportail-Brouage intertidal mudflat, Marennes-Oléron Bay (France). Cont. Shelf Res., 20, 1513-1530.

Hall, S. J. 1994. Physical disturbance and marine benthic communities: life in unconsolidated sediments. Oceanogr. Mar. Biol. Ann. Rev., 32, 179-239.

Haubois, A.-G., J.-M. Guarini, P. Richard, G. F. Blanchard and P.-G. Sauriau. 2002. Spatio-temporal 
differentiation in the population structure of Hydrobia ulvae on an intertidal mudflat (MarennesOléron Bay, France). J. Mar. Biol. Assoc. U.K., 82, 605-614.

Herman, P. M. J., J. J. Middleburg, J. van de Koppel and C. H. R. Heip. 1999. The ecology of estuarine macrobenthos. Adv. Ecol. Res., 29, 195-240.

Houwing, E. J. 1999. Determination of the critical erosion threshold of cohesive sediments on intertidal mudflats along the Dutch Wadden Sea Coast. Estuar. Coast. Shelf Sci., 49, 545-555.

Jumars, P. A. and A. R. M. Nowell. 1984. Effects of benthos on sediment transport: difficulties with functional grouping. Cont. Shelf Res., 3, 115-130.

Jumars, P. A., A. R. M. Nowell and R. F. L. Self. 1981. A simple model of flow-sediment-organism interaction. Mar. Geol., 42, 155-172.

Lavelle, J. W. and H. O. Mofjeld. 1987. Do critical stresses for incipient motion and erosion really exist? J. Hydraul. Eng., 113, 370-388.

Le Hir, P., A. Ficht, R. Silva Jacinto, P. Lesueur, J.-P. Dupont, R. Lafite, I. Brenon, B. Thouvenin and P. Cugier. 2001. Fine sediment transport and accumulations at the mouth of the Seine Estuary (France). Estuaries, 24, 950-963.

Le Hir, P., W. Roberts, O. Cazaillet, M. Christie, P. Bassoulet and C. Bacher. 2000. Characterization of intertidal flat dynamics. Cont. Shelf Res., 20, 1433-1460.

Mehta, A. J. 1988. Laboratory studies on cohesive sediment deposition and erosion, in Physical Processes in Estuaries, J. Dronkers and V. van Leussen, eds., Springer-Verlag, Berlin, 560 pp.

Mehta, A. J. and E. Partheniades. 1982. Resuspension of deposited cohesive sediment beds. Proc. 18th Int. Conf. Coast. Eng. The Cape. 1569-1588.

Nelder, J. A. and R. Mead. 1965. A simplex method for function minimization. Computer J., 7, 308-313.

Orvain, F. 2002. Modelling the influence of benthic organisms on cohesive sediment resuspension in the Marennes-Oléron Bay (France). Ph. D. Thesis, University of La Rochelle, 192 pp.

Orvain, F. and P.-G. Sauriau. 2002. Environmental and behavioural factors affecting bioturbation activities in the intertidal gastropod Hydrobia ulvae. J. Exp. Mar. Biol. Ecol., 272, 191-216.

Partheniades, E. 1965. Erosion and deposition of cohesive soils. J. Hydr. Div. ASCE, 91, 105-139.

Paterson, D. M. and Black, K. S. 1999. Water flow, sediment dynamics and benthic biology. Adv. Ecol. Res., 29, 155-193.

Pearson, T. H. 2001. Functional group ecology in soft-sediment marine benthos: the role of bioturbation. Oceanogr. Mar. Biol. Ann. Rev., 39, 233-267.

Rhoads, D. C. and D. K. Young. 1970. The influence of deposit-feeding organisms on sediment stability and community trophic structure. J. Mar. Res., 28, 150-178.

Sanford, L. P. and J. P.-Y. Maa. 2001. A unified erosion formulation for fine sediments. Mar. Geol., $179,9-23$.

Shimeta, J., C. L. Amos, S. E. Beaulieu and O. M. Ashiru. 2002. Sequential resuspension of protists by accelerating tidal flow: implications for community structure in the benthic boundary layer. Limnol. Oceanogr., 47, 1152-1164.

Sutherland, T. F., C. L. Amos and J. Grant. 1998. The effect of buoyant biofilms on the erodibility of sublittoral sediments of a temperate microtidal estuary. Limnol. Oceanogr., 43, 225-235.

van der Ham, R. and J. C. Winterwerp. 2001. Turbulent exchange of fine sediments in a tidal channel in the Ems/Dollard estuary. Part II. Analysis with a 1DV numerical model. Cont. Shelf Res., 21, 1629-1647.

Widdows, J., M. Brinsley, P. N. Salkeld and C. H. Lucas. 2000a. Influence of biota on spatial and temporal variation in sediment erodability and material flux on a tidal flat (Westerschelde, The Netherlands). Mar. Ecol. Prog. Ser., 194, 23-37.

Widdows, J., S. Brown, M. D. Brinsley, P. N. Salkeld and M. Elliott. 2000b. Temporal changes in 
intertidal sediment erodability: influence of biological and climatic factors. Cont. Shelf Res., 20, 1275-1289.

Willows, R. I., J. Widdows and R. G. Wood. 1998. Influence of an infaunal bivalve on the erosion of an intertidal cohesive sediment: a flume and modeling study. Limnol. Oceanogr., 43, 1332-1343. Wood, R. and J. Widdows. 2002. A model of sediment transport over an intertidal transect, comparing the influences of biological and physical factors. Limnol. Oceanogr., 47, 848-855.

Received: 22 May, 2003; revised: 8 December, 2003. 